Research Paper

\title{
Estrogen related receptor alpha in castration-resistant prostate cancer cells promotes tumor progression in bone
}

\author{
Anais Fradet ${ }^{1,2, *}$, Mathilde Bouchet $^{1,2, *}$, Carine Delliaux ${ }^{3,4}$, Manon Gervais ${ }^{1,2}$, \\ Casina Kan ${ }^{1,2}$, Claire Benetollo 2,5 , Francesco Pantano ${ }^{6}$, Geoffrey Vargas ${ }^{1,2}$, Lamia \\ Bouazza $^{1,2}$, Martine Croset $^{1,2}$, Yohann Bala ${ }^{1,2}$, Xavier Leroy ${ }^{7}$, Thomas J Rosol $^{8}$, \\ Jennifer Rieusset ${ }^{9}$, Akeila Bellahcène ${ }^{10}$, Vincent Castronovo ${ }^{10}$, Jane E Aubin ${ }^{11}$, \\ Philippe Clézardin ${ }^{1,2}$, Martine Duterque-Coquillaud ${ }^{3,4}$, Edith Bonnelye ${ }^{1,2}$ \\ ${ }^{1}$ InsermUMR1033, F-69372 Lyon, France \\ ${ }^{2}$ Université-Lyon1, F-69008 Lyon, France \\ ${ }^{3}$ CNRS-UMR8161, F-59021 Lille, France \\ ${ }^{4}$ Université-Lille, F-59000 Lille, France \\ ${ }^{5}$ InsermU1028-CNRS-UMR5292, Lyon, France \\ ${ }^{6}$ University-Campus-Bio-Medico, 00128 Rome, Italy \\ ${ }^{7}$ Centre Hospitalier Lille, F-59037 Lille, France \\ ${ }^{8}$ College of Veterinary Medicine, Columbus, OH 43210, USA \\ ${ }^{9}$ InsermUMR-U1060, F-69921 Oullins, France \\ ${ }^{10}$ University Liege, B-4000 Liege, Belgium \\ ${ }^{11}$ University of Toronto, Toronto, ON M5S 1A8, Canada \\ * These authors contributed equally to this work
}

Correspondence to: Edith Bonnelye, email: edith.bonnelye@inserm.fr Keywords: ERRa, bone, prostate cancer, microenvironment

Received: July 04, 2016 Accepted: October 13, $2016 \quad$ Published: October 20, 2016

\section{ABSTRACT}

Bone metastases are one of the main complications of prostate cancer and they are incurable. We investigated whether and how estrogen receptor-related receptor alpha (ERRa) is involved in bone tumor progression associated with advanced prostate cancer. By meta-analysis, we first found that ERRa expression is correlated with castration-resistant prostate cancer (CRPC), the hallmark of progressive disease. We then analyzed tumor cell progression and the associated signaling pathways in gain-offunction/loss-of-function CRPC models in vivo and in vitro. Increased levels of ERRa in tumor cells led to rapid tumor progression, with both bone destruction and formation, and direct impacts on osteoclasts and osteoblasts. VEGF-A, WNT5A and TGF 11 were upregulated by ERRa in tumor cells and all of these factors also significantly and positively correlated with ERRa expression in CRPC patient specimens. Finally, high levels of ERRa in tumor cells stimulated the pro-metastatic factor periostin expression in the stroma, suggesting that ERRa regulates the tumor stromal cell microenvironment to enhance tumor progression. Taken together, our data demonstrate that ERRa is a regulator of CRPC cell progression in bone. Therefore, inhibiting ERRa may constitute a new therapeutic strategy for prostate cancer skeletal-related events.

\section{INTRODUCTION}

Bone metastases are a frequent complication of cancer occurring in up to $80 \%$ of patients with advanced prostate cancer $(\mathrm{PCa})$ and castration-resistance (CRPC "castration-resistant prostate cancer") with associated poor five-year survival rate $[1,2]$. They are not curable and result in impaired mobility and pathological fractures [3]. To grow in bone, tumor cells alter bone formation and resorption by secreting proteins that 
directly affect osteoblasts (bone-forming cells) and osteoclasts (bone-resorbing cells) resulting in the development of mixed lesions [1,4]. These signaling proteins may include RANKL (receptor activator of the NF-kB ligand) which stimulates osteoclast differentiation $[1,5]$ and osteoprotegerin (OPG) which acts as a decoy receptor for RANKL receptor and inhibits osteoclastogenesis [5]. Therefore, the balance between RANKL and OPG is critical in controlling osteoclast activity and osteolysis in bone metastases. PCa cells also express factors such as TGF $\beta$ (transforming growth factor beta), WNT family members such as Wnt5a and the pro-angiogenic factor VEGFA that promote an aggressive tumor phenotype and bone metastases by directly affecting osteoclast and osteoblast formation $[6,7]$. The induction of stromal niche signals by tumor cells, for example expression of extracellular matrix proteins such as PERIOSTIN (POSTN) in the tumor microenvironment, also contributes to the expansion of the metastatic niches [8-11].

Nuclear receptors are transcription factors that comprise ligand-dependent molecules, such as estrogen receptors (ERs), and a large number of so-called orphan receptors for which no ligand has yet been determined [12]. Estrogen receptor-related receptor alpha $(\operatorname{ERR} \alpha)$ (NR3B1) shares structural similarities with $\mathrm{ER} \alpha$ and ER $\beta$ (NR3A1/NR3A2) [13] but does not bind estrogen [14]. Since very recently, ERR $\alpha$ was considering as the oldest orphan receptor but Wei et al. just described the cholesterol as a potential ERR $\alpha$ agonist [15]. Synthetic molecules like the inverse agonist XCT-790 were also designed to block ERR $\alpha$ activity by preventing its interaction with the co-activators peroxisome proliferator-activated receptor gamma coactivator (PGC1) [16].

ERR $\alpha$ is expressed in a range of cancer cell types and ERR $\alpha$-positive tumors (breast and prostate) are associated with more invasive disease and higher risk of recurrence $[17,18]$. Indeed in prostate cancer, ERR $\alpha$ is significantly higher in cancerous lesions compared to benign foci and high level of ERR $\alpha$ correlates with Gleason score and poor survival [18]. Moreover, in androgen receptor (AR)-positive models, ERR $\alpha$ has been implicated in AR signaling pathways and shown to increase HIF-1 signaling and to promote hypoxic growth adaptation of prostate cancer cells $[19,20]$. ERR $\alpha$ is also expressed in bone where it regulates differentiation and activity of osteoblasts and osteoclasts, both of which are implicated into the mixed osteolytic and osteoblastic lesions observed in advanced prostate cancer patients [15] [21]. Based on our previous data in bone metastases from breast cancer [22], and on the fact that bone metastases are the hallmark of progressive disease and CRPC, mainly characterized by AR alterations [23], we investigated whether and how ERR $\alpha$ is involved in bone progression of CRPC (AR-negative) models.

\section{RESULTS}

\section{ERR $\alpha$ is more highly expressed in CRPC patients and their associated bone metastases than normal prostate and non-metastasizing PCa}

To determine whether ERR $\alpha$ is involved in PCa bone lesions, we first assessed ERR $\alpha$ mRNA expression (ESRRA) levels during disease progression by performing a meta-analysis of data from the gene expression omnibus (GEO; GSE69129, GSE21034 and GSE32269) (Figure 1A-1C, Supplementary Table $\mathrm{S} 1)[24,25,26]$. We found that $E R R \alpha$ expression was significantly higher in CRPC compared to normal prostate $(P=0.0172)$ (Figure $1 \mathrm{~A})$ and $(P=<0.05, n$ $=22$ (normal) vs $n=41$ (CRPC)) (Figure 1B). Higher $E R R \alpha$ expression was also observed in primary tumors from CRPC patients who had developed bone metastases compared to androgen-sensitive $\mathrm{PCa}$ patients $(P<0.005$, (PCa) vs (CRPC bone Mets))(Figure 1B) and $(P=0.0178$, (PCa) vs (CRPC who all developed bone metastases)) (Figure 1C). In the dataset GSE21034, we also found that $E R R \alpha \mathrm{mRNA}$ was significantly higher in primary cancerous prostate lesions from CRPC who developed bone metastatic lesions $(n=5)$ compared to patients with had developed other types of metastases (brain, lung, bladder, colon or lymph nodes) $(n=41)$ $(P<0.05$; Figure 1B) suggesting that $E R R \alpha$ is associated with advanced prostate cancer and bone metastases. Immunohistochemistry also revealed that $E R R \alpha$ protein expression in human PCa cells was maintained in the associated bone metastases (Figure 1D), suggesting that ERR $\alpha$ is an overall poor prognostic factor for bone metastases from CRPC.

\section{ERRa in PCa cells promotes tumor cells progression in vivo in bone microenvironment}

To address ERR $\alpha$ function in PCa bone progression, we used three CRPC pre-clinical models, two human models (PC3 and PC3c) and one canine model (ACE-1). Specifically, a full-length $E R R \alpha$ cDNA was stably transfected into PC3 cells, which are known for their capacity to form osteolytic lesions in vivo [27]. Three independent PC3-ERR $\alpha$ clones (overexpressing ERR $\alpha$ ) and three PC3-CT clones (harboring empty vector) were generated (Figure 1E, 1F). In parallel, to validate further the human PC3 model, human PC3c and canine ACE-1 PCa cells that both induce mixed bone lesions (with both osteolysis and osteoformation) were stably transfected with full-length ERR $\alpha$ cDNA (Figure 1H, 1J) [28] [29]. ACE-1 cells were also transfected with cDNA containing a truncated form of ERR $\alpha$ lacking the co-activator binding domain AF2 (AF2) (Figure 1J) [22]. Western blotting confirmed higher ERR $\alpha$ expression in PC3-ERR $\alpha, \mathrm{PC} 3 \mathrm{c}-$ $\mathrm{ERR} \alpha$ and $\mathrm{ACE}-1-\mathrm{ERR} \alpha$ than in their respective control 
cells (Figure 1E, 1H, 1J). The presence of a slightly lower molecular weight band in AF2 in ACE-1 cells expressing the ERR $\alpha$-AF2 deletion mutant corresponded well with its expected smaller size (AF2; Figure 1J) [22]. As expected, expression of mRNA for $V E G F-A$, a known $E R R \alpha$ target gene [30] was higher in all of the $E R R \alpha$ overexpressing clones (ERR $\alpha$; PC3, PC3c and ACE-1) but not in the AF2 ACE-1 clone, confirming the increased activity and the dominant negative functions of both wild-type $E R R \alpha$ and the truncated $E R R \alpha-A F 2$ constructs respectively (Figure $1 \mathrm{G}, 1 \mathrm{I}, 1 \mathrm{~K})$. To assess whether and how levels of $E R R \alpha$ in tumor cells affected progression of bone lesions, PC3, PC3c and ACE-1 clones were inoculated via intratibial injections into SCID male mice (Figure 2). Three weeks (for PC3 (pool of the 3 clones for CT and ERR $\alpha$ respectively) and ACE-1 clones) (Figure 2 (PC3 (A-E), ACE-1 (K-Q)) and six weeks (for PC3c clones) (Figure 2 $\mathrm{PC} 3 \mathrm{c}(\mathrm{F}-\mathrm{J})$ ) after tumor cell injections, radiographs revealed that animals bearing $E R R \alpha$ overexpressing tumors had increased bone lesion surfaces whereas ACEAF2 tumors had decreased bone lesion surface compared to CT tumors (Figure 2 -PC3 (A-B), (Mann-Whitney, $P=0.011$ ) (bone lesion surface $\left.\mathrm{mm}^{2}\right)(\mathrm{E}),-\mathrm{PC} 3 \mathrm{c}(\mathrm{F}-\mathrm{G})$, (Mann-Whitney, $P=0.0175)(\mathrm{J})$-ACE-1 (K-M) (MannWhitney, $P=0.0079, P=0.0304$ ) (Q)). The stimulatory effect of ERR $\alpha$ on PCa-induced bone lesion surface was confirmed by three-dimensional micro-computed tomographic reconstruction $(\% \mathrm{BV} / \mathrm{TV})$ (cortical and
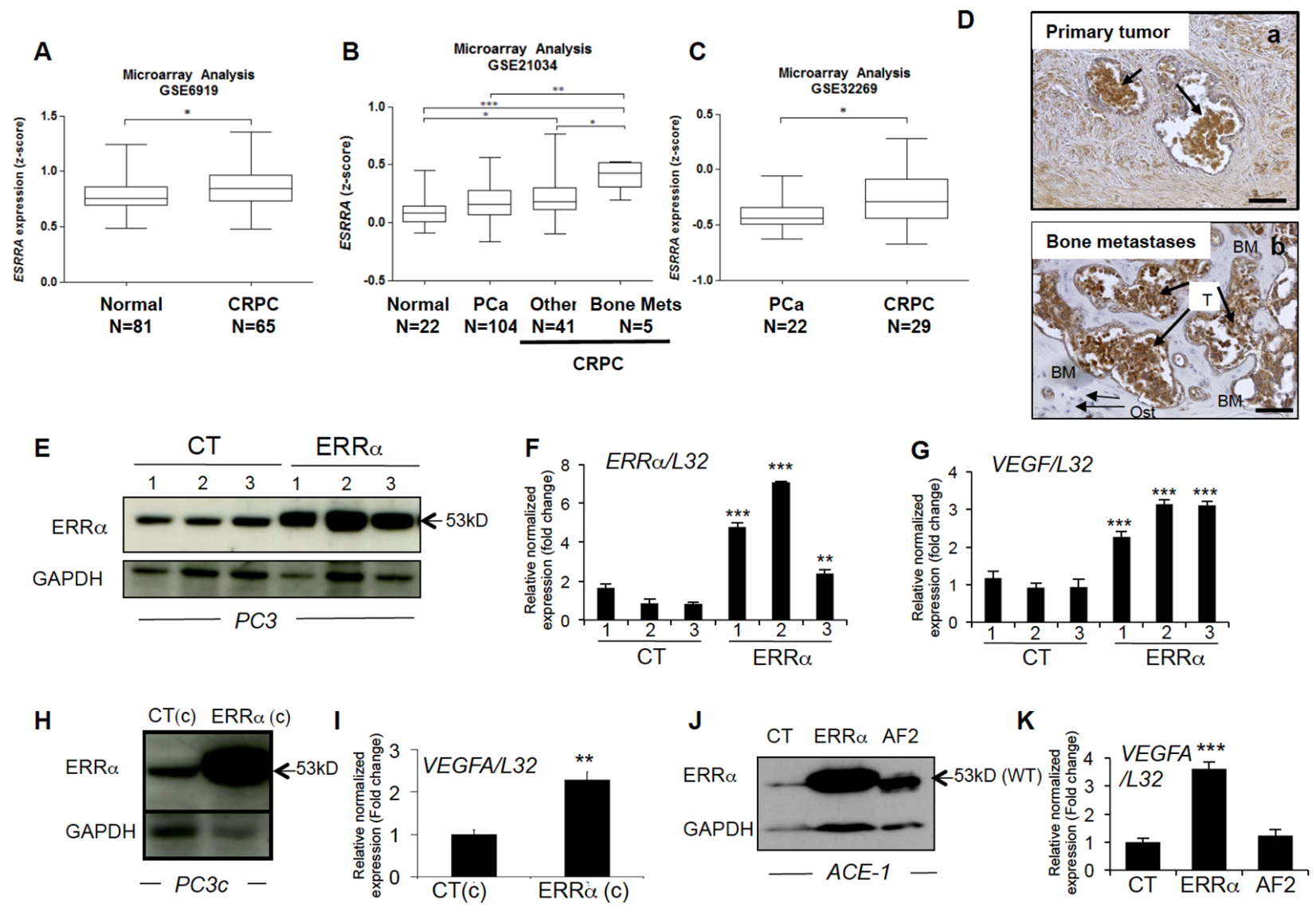

Figure 1: ERR $\alpha$ expression and CRPC from PCa patients. (A) Meta-analysis using public datasets showed that $E R R \alpha$ mRNA expression is higher in CRPC patients in GSE6919 (Student's $t$-test $P=0.0172$ ). (B) $E R R \alpha$ was also found to be higher in CRPC compared to androgen-sensitive $\mathrm{PCa}$, as well as in primary tumors from CRPC patients that developed metastases to bone compared to other sites or normal prostate tissues in GSE21034 (One way ANOVA, bonferri post-hoc test : $P<0,05$, normal $(n=22)$ versus CRPC $(n=41)$; $P<0.0005$, normal $(n=22)$ versus CRPC bone mets $(n=5) ; P<0.005$, PCa $(n=104)$ versus CRPC bone mets $(n=5))$ and $(\mathbf{C})$ PCa versus CRPC (that all had developed bone metastases) in GSE32269 (Student's $t$-test $P=0.0178$ ): ${ }^{*} P<0.05,{ }^{*} P<0.005$, ${ }^{*} * * P 0.0005$. (D) Visualization of ERR $\alpha$ protein expression by IHC on sections of prostate primary tumor (a) and the associated bone metastatic lesions (b) from the same patient. (E) Assessment of ERR $\alpha$ expression by Western blotting and (F) real-time RT-PCR on triplicate samples and normalized against the ribosomal protein gene $L 32$ (ANOVA, Student's $t$-tests $P<0.0001)$ in PC3 control (CT-1-3) and PC3-ERR $\alpha(E R R \alpha-1-3)$ overexpressing $E R R \alpha$ clones. (G) Increased expression of $V E G F-A$ mRNA in PC3-ERR $\alpha$ (ANOVA, Student's $t$-tests $P<0.0001)$. (H) Increase of ERR $\alpha$ protein expression in PC3c-ERR $\alpha(E R R \alpha(c))$ overexpressing ERR $\alpha$ shown by Western blot and (I) by real-time RT-PCR for $V E G F-A$ expression (Student's $t$-tests $P=0.001)$. (J) Assessment of $E R R \alpha$ expression by Western blotting in an ACE-1 empty-vector CT clone, an ACE-ERR $\alpha$ and a clone overexpressing the dominant negative ERR $\alpha$ with AF2 domain deletion (AF2). (K) $V E G F-A$ mRNA expression was also increased in ACE-ERR $\alpha$ cells (Student's $t$-tests $P=0.0001)$. Bar $=200 \mu \mathrm{m}$, T: Tumor; Ost: osteocytes; BM: Bone Matrix 
trabecular bone), with a decrease in bone volume in animals bearing PC3-ERR $\alpha$ and ACE-1-ERR $\alpha$ tumors (\%BV/TV, Mann-Whitney, PC3 $P=0.022$ and, ACE-1 $P=0.0411)$ suggesting an increase in bone destruction in both ERR $\alpha$ overexpression models (Figure 2E and $2 \mathrm{Q}, \% \mathrm{BV} / \mathrm{TV})$. The stimulatory effect of $E R R \alpha$ on PCainduced bone lesion surface was also evident by histology (Figure 2 PC3(C,D)) and histomorphometric analysis (TB/ STV) with an increase of skeletal tumor burden (Figure $2 \mathrm{E}$ and 2Q). Since the osteoblastic region is highly stimulated in the PC3c model (Figure 2H, 2I) (see the increased of the $\% \mathrm{BV} / \mathrm{TV}$ : (Mann-Whitney, $P=0.022)$ ), the surface of the tumor (TB/STV) decreased in animals bearing PC3cERR $\alpha$ (Figure 2J (Mann-Whitney, $P=0.0023$ )) (asterisks showing bone formation). Similarly, $70 \%$ of mice bearing PC3-ERR $\alpha$ tumors exhibited small new bone formation compared to mice bearing PC3-CT tumors (Figure 2E). New bone formation was also seen in animals bearing ACE-1-ERR $\alpha$ versus ACE-1-CT tumors (Figure 2Q: extra-bone-new spicules surface formation/ tissue volume; Figure 2 (N-P) (asterisks mark extra-new spicules bone formation). The bone lesion surface and bone volume-new
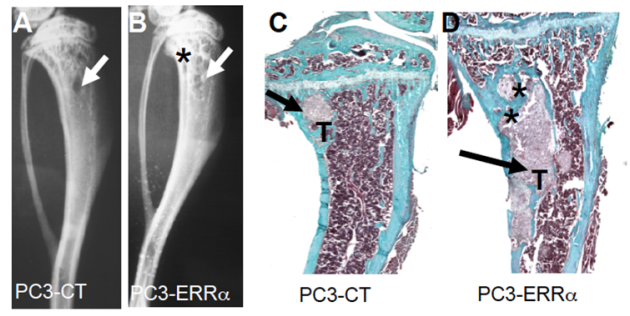

E
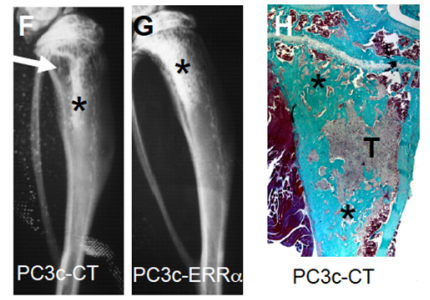

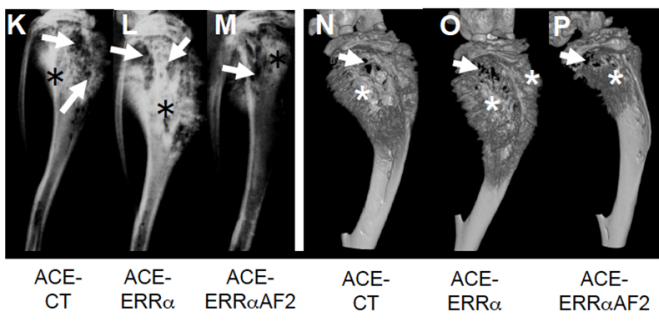

Figure 2: Over-expression of $\boldsymbol{E R R} \boldsymbol{\alpha}$ in prostate cancer cells induced bone lesions development. Radiography revealed larger lesions in mice injected with (A, B) PC3-ERR $\alpha$ versus PC3-CT, and (F, G) with PC3c-ERR $\alpha$ versus PC3c-CT. Histology after Goldner's trichrome staining confirmed the radiography results in mice injected with $(\mathbf{C}, \mathbf{D})$ PC3-ERR $\alpha$ versus PC3-CT $(\mathbf{H}, \mathbf{I})$ with PC3c-ERR $\alpha$ versus PC3c-CT (bone matrix in green). (E) Induction -of larger bone lesions surface in mice injected with PC3-ERR $\alpha(E R R \alpha)(M a n n-W h i t n e y$, $P=0.011$ ), -of a decrease in \%BV/TV (Mann-Whitney, $P=0.022$ ) and an increase of \%TB/STV (Mann-Whitney, $P=0.008$ ) compared with mice injected with PC3-CT (CT). Bone formation incidence show that 70\% of mice injected with PC3-ERR $\alpha(E R R \alpha)$ developed some bone formation as opposed to $10 \%$ of mice injected with PC3-CT (CT). (J) Increased -of bone lesions surface in mice injected with PC3c-ERR $\alpha$ (Mann-Whitney, $P=0.0175$ ), -of the \%BV/TV (Mann-Whitney, $P=0.022$ ) and decrease of the \%TB/STV (Mann-Whitney, $P=0.0023)$ compared with mice injected with PC3c-CT (CT). Radiography $(\mathbf{K}-\mathbf{M})$ and 3D micro-tomography reconstructions $(\mathbf{N}-\mathbf{P})$ showed larger bone lesions in mice injected with ACE-ERR $\alpha$ versus ACE-CT with an abrogation of the bone lesion effects seen with ERR $\alpha$ overexpression in tumors bearing the dominant negative AF2-truncated ERR $\alpha$. (Q) After 3 weeks post inoculation of ACE-ERR $\alpha$, ACECT and ACE-AF2 cells, radiography revealed larger and smaller bone lesions surface in mice injected with ACE-ERR $\alpha$ and ACE-AF2 respectively compared to CT (Mann-Whitney, $P=0.0079, P=0.0304$ ) and microtomographic reconstructions of tibiae show a decrease in mice injected with ACE-ERR $\alpha$ compared to CT (\%BV/TV: Mann-Whitney, $P=0.0411)$, an increase in $\%$ TB/STV (Wilcoxon, $P=0.034)$ compared to CT, and an increase in \% new bone formation/TV (extra-bone spicules formation): (Mann-Whitney, $P=0.0025$ ). The increase in bone lesion surface (Mann-Whitney, $P=0.0011$ ), in the \%TB/STV (Mann-Whitney, $P=0.0052$ ), in the extra-bone spicules formation (Mann-Whitney, $P=0.0012$ ) and the decrease in \%BV/TV (Wilcoxon, $P=0.0273$ ) effects seen with ERR $\alpha$ overexpression were markedly abrogated in tumors bearing the dominant negative AF2-truncated ERR $\alpha .{ }^{*}=P<0.05 ; * *=P<0.001 ; * * *=P<0.0001$. T: Tumor;

* bone formation; Arrow: bone degradation. 
bone formation effects seen with ERR $\alpha$ overexpression were markedly abrogated in tumors bearing the dominant negative AF2-truncated ERR $\alpha$ (Figure $2 \mathrm{~K}, 2 \mathrm{M}$ and $2 \mathrm{~N}, 2 \mathrm{P}$, 2Q). Taken together, our results indicate that overexpression of ERR $\alpha$ in PCa cells stimulates both new bone formation and destruction suggesting that it may be associated with mechanisms mediating mixed lesions in vivo.

\section{Modulation of ERRa expression in cancer cells affects the bone microenvironment}

Since our in vivo data suggested an impact of ERR $\alpha$ expression levels on $\mathrm{PCa}$-induced bone destruction and formation, we next assessed whether PCa overexpressing ERR $\alpha$ cells affected osteoclasts (bone-resorbing cells) and osteoblasts (bone-forming cells). A 40\% increase in TRAP-positive osteoclast surface $(\% \mathrm{Oc} . \mathrm{S} / \mathrm{BS})$ was seen at the bone-tumor cell interface in PC3-ERR $\alpha$ tumors (Figure 3A). Consistent with these in vivo data, the number of TRAP-positive cells (Figure 3B) and the expression of osteoclast markers (trap, ck, caII and rank) (Figure 3C) were higher in co-cultures of primary mouse bone marrow cells with PC3-ERR $\alpha$ cells compared to PC3-CT cells
[5]. Moreover, treatment of bone marrow cells by the conditioned medium obtained from parental PC3 cells treated with the inverse agonist XCT-790, which blocks ERR $\alpha$ activity, inhibited osteoclast formation (Figure 3D). Similarly, PC3c- ERR $\alpha$ cells co-cultured with primary mouse bone marrow cells also stimulated osteoclast formation compared to PC3c-CT cells (Figure 3E), as did ACE-1-ERR $\alpha$ compared to ACE-1-CT cells while ACE-1-AF2 inhibited osteoclastogenesis compared to ACE-1-ERR $\alpha$ (Figure 3F) suggesting that cancerous cells expressing ERR $\alpha$ increase osteoclastogenesis.

The increased bone formation observed in vivo suggests that changes in ERR $\alpha$ expression in PCa cells also alters the differentiation of osteoblasts. Consistent with this hypothesis, a higher number of bone nodules formed in primary mouse calvaria cells cultured with PC3ERR $\alpha$ versus PC3-CT conditioned medium (Figure 4A). Similarly, the expression of the osteoblastic markers alkaline phosphatase ( $a l p)$, bone sialoprotein ( $b s p)$ and osteocalcin (ocn) increased (Figure 4C) in co-cultures of MC3T3-E1 and PC3-ERR $\alpha$ cells $(E R R \alpha)$ (Figure 4C) [31]. The pro-osteoclastic factors rankl but not opg, was increased in MC3T3-E1 cells co-cultured with PC3-ERR $\alpha$
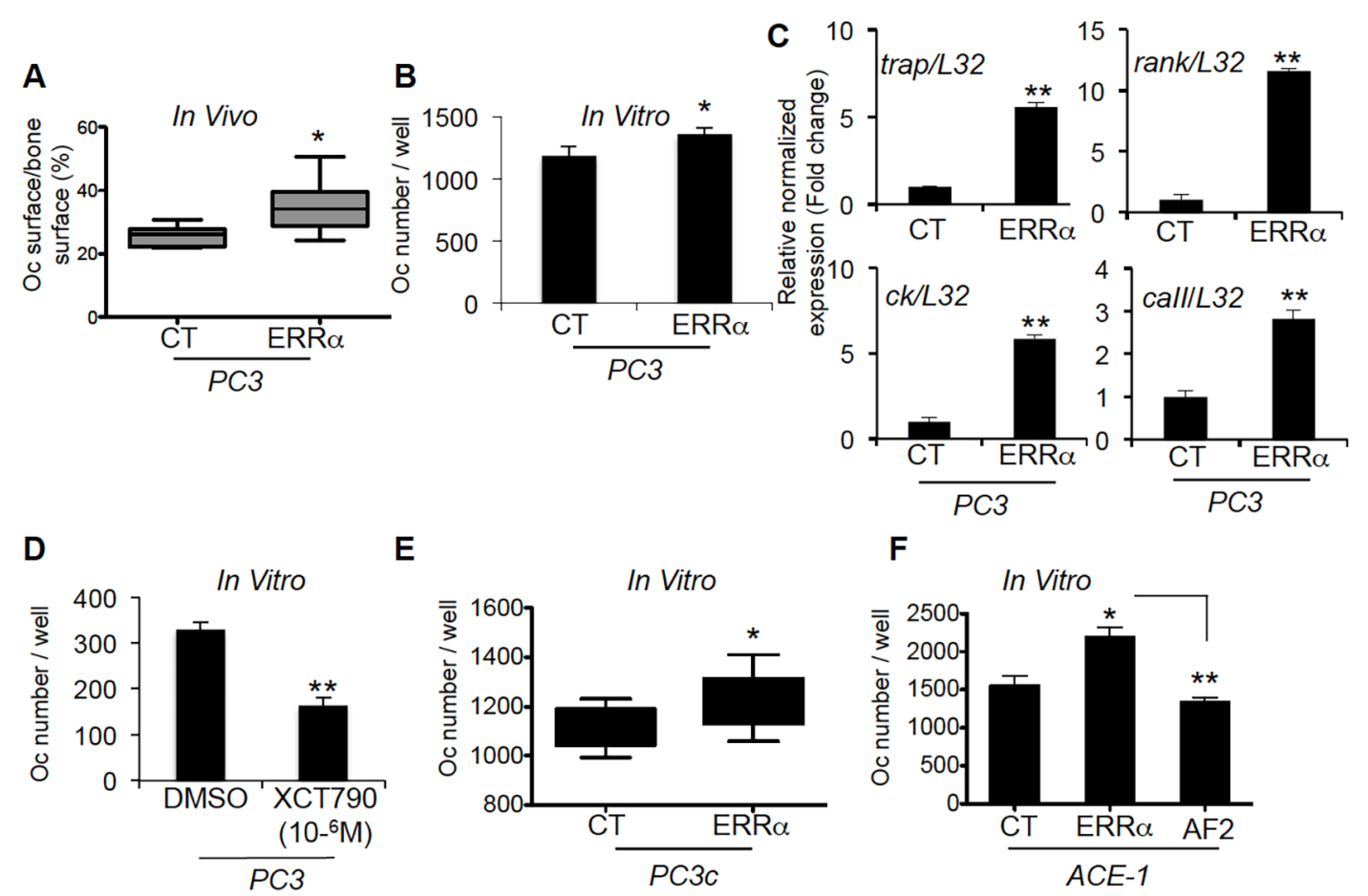

Figure 3: ERRa overexpression in PCa-ERRa cells modified bone-resorbing cells. (A) Increase in osteoclast (Oc) surface in bone lesions induced by PC3-ERR $\alpha$ cells in vivo (\%Oc.S/BS: Mann-Whitney, $P=0.0062 ; n=7$ (CT) and $n=10$ (ERR $\alpha)$ ). (B) PC3-ERR $\alpha$ cells increase the number of TRAP+ osteoclasts in vitro (Oc number/well: paired $t$-test, $P=0.0275)$. (C) mRNA was extracted from cocultures on day 7. The expression of trap (Tartrate Resistant Acid Phosphatase), ck (Cathepsin K), rank and caII (Carbonic Anhydrase II) was assessed by real-time RT-PCR on triplicate samples; all markers were higher in Oc/PC3-ERR $\alpha$ (ERR $\alpha)$ versus Oc/PC3-CT (Student's $t$-tests, $P=0.0026 ; P=0.0055, P=0.0057 ; P=0.008)$. (D) Conditioned medium obtained from parental PC3 cells treated with the inverse agonist XCT-790 decreased Oc formation, confirming the results obtained with PC3-ERR $\alpha$ (Student's $t$-tests, $P=0.0023$ ). (E-F) PC3c$\mathrm{ERR} \alpha(\mathrm{E})$ and ACE-ERR $\alpha(\mathrm{F})$ increased the number of TRAP+ osteoclasts in vitro compared to the respective controls (Oc number/well: paired $t$-test, $P=0.022$ (PC3c-ERR $\alpha$ versus PC3C-CT) and ANOVA $p=0.0048, P<0.05$ (ACE-1-ERR $\alpha$ versus ACE-1-CT) while ACE-1AF2 inhibited Oc formation $P<0.005$ (ACE-1-AF2 versus ACE-1-ERR $\alpha$ ). Oc results are representative of two independent experiments, each performed in triplicate samples. 
cells (Figure 4D). Consistent with this, we observed a trend towards an increase in the number of bone nodules formed in primary mouse calvaria cells cultured with PC $3 c-E R R \alpha$ conditioned medium (Figure 4B) and an increase in osteoblastic markers $b s p$ and ocn expression in co-cultures of MC3T3-E1 and ACE-1-ERR $\alpha$ cells $(E R R \alpha)($ Figure 4E). In contrast, no change in expression of either osteoblastic markers was detected in co-cultures of MC3T3-E1 with ACE-1-AF2 cells (Figure 4E). Also no regulation of rankl and opg expression was noticed (Figure 4F). Taken together, our results suggest that ERR $\alpha$ expression in $\mathrm{PCa}$ cells induces changes in osteoblast lineage cells.

\section{Identification of two factors regulated in PCa cells that couple bone resorption and formation: VEGFA and Wnt5a}

Since both osteoclasts and osteoblasts are stimulated by PCa cells overexpressing ERR $\alpha$, we next sought to identify factors secreted by PCa cells that may stimulate both lineages. As shown earlier, PC 3, PC 3c and ACE-1 cells overexpressing ERR 2 stimulate expression of $V E G F-A$ (Figure $1 \mathrm{G}, \mathrm{I}, \mathrm{K}$ ), a known ERR $\alpha$ target and stimulator of osteoblasts and osteoclasts [32, 33]. By immunohistochemistry, ERRa (Figure 5A, 5B) and $V E G F-A$ (Figure 5C, 5D) expression was observed in $\mathrm{PCa}$ cells and higher in PC3-ERR $\alpha$-induced bone lesions in vivo (Figure 5B and 5D respectively) compared to PC3-CT lesions (Figure 5A and 5C respectively). Regulation of $V E G F-A$ by $\mathrm{ERR} \alpha$ was confirmed in vitro in PC3 cells transfected with a pool of three ERR $\alpha$-siRNA sequences (Si) compared to control sequences (Sc) (Figure 5E-5G). Blocking ERR $\alpha$ activity by treating PC3-ERR $\alpha$ cells with the ERR $\alpha$ inverse agonist XCT-790 also demonstrated a statistical down-regulation of $V E G F-A$ (Figure $5 \mathrm{H}$ ). That ERR $\alpha$ regulates $V E G F-A$ in both non-bone and bone microenvironments was determined by assessing subcutaneous (SC) tumors obtained by injecting PC3-ERR $\alpha$ and PC3-CT clones in male SCID mice. $V E G F-A$ expression was higher in PC3-ERR $\alpha(E R R \alpha)$-tumors compared to PC3-CT (CT)-induced SC tumors in vivo (Figure 5I-5J). The correlation of increased $E R R \alpha$ and increased $V E G F-A$ expression was confirmed in PC3c-ERR $\alpha$-induced bone
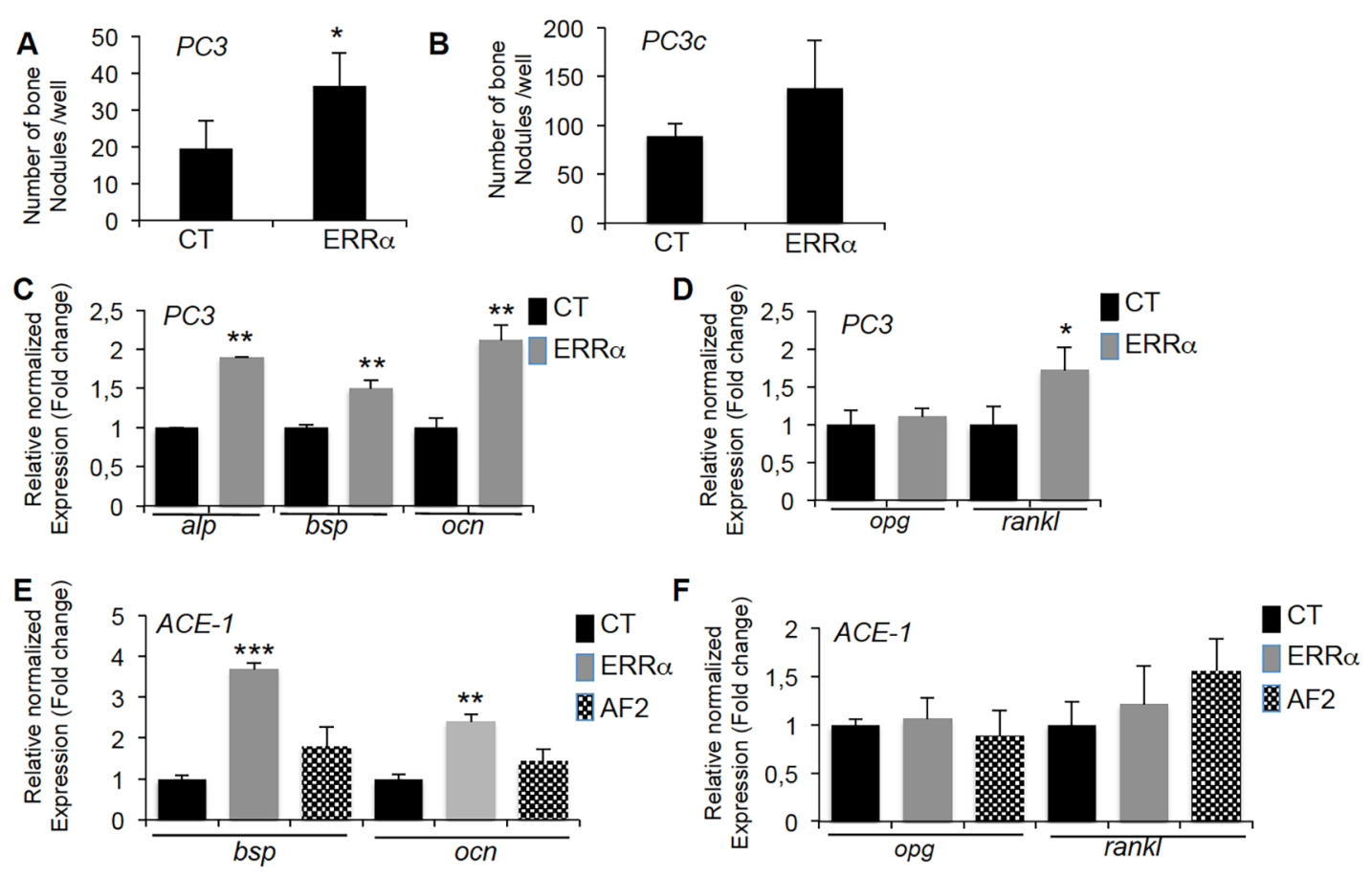

Figure 4: ERR $\alpha$ overexpression in PCa-ERR $\boldsymbol{\alpha}$ cells stimulates bone-forming cells. (A) Osteoblasts (Ob) from primary mouse calvaria cell cultures were treated with conditioned medium of PC3-ERR $\alpha(E R R \alpha)$ or PC3-CT (CT) cells. Bone nodule number was higher in co-cultures with PC3-overexpressing ERR $\alpha(\mathrm{Ob}-\mathrm{ERR} \alpha)$ (Mann-Whitney, $P=0.0118)$. (B) When treated with conditioned medium of $\mathrm{PC} 3 \mathrm{c}-\mathrm{ERR} \alpha(\mathrm{ERR} \alpha)$, bone nodule number was increased but not significantly compared to PC3c-CT (CT). (C) Confirming mouse calvaria results, co-cultures of PC3-ERR $\alpha(\mathrm{ERR} \alpha)$ or PC3-CT (CT) cells with the MC3T3-E1 osteoblastic cell line for 2 weeks stimulated expression of osteoblastic markers alp (Alcalin Phosphatase), bsp (bone sialoprotein) and ocn (osteocalcin) (ANOVA, $P<0.0001$; Student's $t$-tests, $P=0.0031 ; P=0.0098 ; P=0.0017$ ) (D) Expression of rankl mRNA was also higher (ANOVA, $P<0.0001$, Student's $t$-tests, $P=0.0279$ ) while opg expression was not altered. (E) Co-cultures of ACE-1-ERR $\alpha(E R R \alpha)$ or ACE-1-CT (CT) cells with the MC3T3-E1 osteoblastic cell line for 2 weeks also stimulated bsp and ocn mRNA expression (ANOVA bsp, $\mathrm{P}=0.004$; Student's $t$-tests, $\mathrm{P}=0.0003$ (ACE-1-CT versus ACE-1-ERR $\alpha$ ); ANOVA ocn, $P=0.0069$; Student's $t$-tests, $P=0.0067$ (ACE-1-CT versus ACE-1-ERR $\alpha$ ) while no regulation was observed with ACE-1-AF2 cells (AF2). (F) Expression of rankl and opg mRNA was not regulated. Ob results are representative of two independent experiments, each performed in triplicate samples. 
lesions in vivo (Figure 5L, 5N) compared to PC3c-CT lesions (Figure $5 \mathrm{~K}, 5 \mathrm{M}$ ). It is interesting to mention that beside tumor mass, vegf- $a$ was also highly expressed in peritumoral cells in PC3c-CT and PC3c-ERR $\alpha$ (Figure 5M, 5N) compared to PC3-CT and PC3-ERR $\alpha$ - induced bone lesions in vivo (Figure 5C, 5D). This peri-tumoral vegf- $a$ expression that probably contributes to the formation of the mixed phenotype observed in PC $3 \mathrm{c}$ cells, was not modulated in PC3-ERR $\alpha$ - induced bone lesions in vivo compared to CT. Finally, in line with our pre-clinical models, we found that $V E G F-A$ positively correlated with ERR $\alpha$ expression levels in primary CRPC tumor samples from combined microarray datasets GSE1034, GSE6919 and GSE2269 $(n=140, r=$ $0.364, P<0.0001)$ and in bone metastases (GSE29650, GSE41619 and GSE74685) [34-36] $(n=64, r=0.646, P<$ 0.0001) (Table 1; Supplementary Table S1).

The second factor that was found upregulated by ERR $\alpha$ in our human preclinical models is WNT5A, a factor also known to stimulate osteoblasts and osteoclasts
[37] and previously linked to ERR $\alpha$ in osteoblasts [38]. Thus, WNT5A expression was higher in ERR $\alpha$ overexpressing PC3 cells (PC3-ERR $\alpha$ ) compared to PC3-CT clones (Figure 6A), and down-regulating ERR $\alpha$ levels in PC3 cells with ERR $\alpha$-SiRNA (pool of three sequences) decreased $W N T 5 A$ expression compared to control sequences (Sc, Figure 6B). WNT5A expression was also upregulated in PC3-ERR $\alpha-$ versus PC3-CTinduced bone lesions in vivo (Figure $6 \mathrm{C}$, a versus b). XCT-790 treated PC3-ERR $\alpha$ cells also demonstrated a down-regulation of WNT5A expression (Figure 6D). Stimulation of WNT5A expression by ERR $\alpha$ was also confirmed in PC3-ERR $\alpha$ - versus PC3-CT-induced SC tumors in vivo (Figure 6E), and in PC3c-ERR $\alpha$-versus $\mathrm{PC} 3 \mathrm{c}-\mathrm{CT}$ clones in vitro (Figure 6F) as well as in PC3c$\mathrm{ERR} \alpha$ versus $\mathrm{PC} 3 \mathrm{c}-\mathrm{CT}$-induced bone lesions in vivo (Figure 6G, a versus b). Notably, WNT5A expression also positively correlated with ERR $\alpha$ expression levels in bone metastases microarray datasets (GSE29650, GSE41619

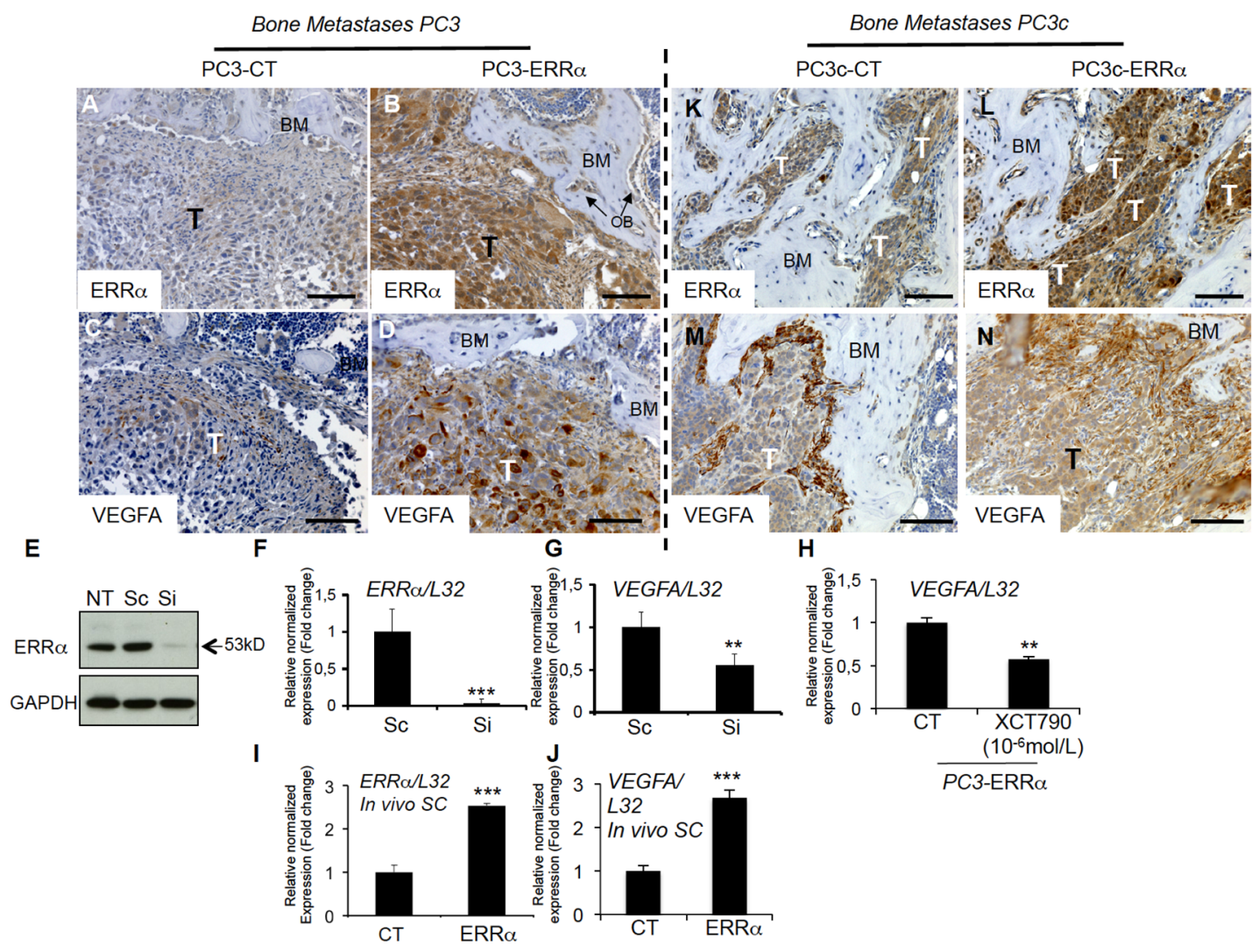

Figure 5: Stimulation of $\boldsymbol{V E G F}$ - $\boldsymbol{A}$ expression in PCa cells by ERRa. (A-B) Visualization of the overexpression of $E R R \alpha$ protein expression in tumor by IHC on bone lesions in vivo induced by PC3-ERR $\alpha(E R R \alpha)(B)$ compared PC3-CT (CT)(A). (C-D) Paralleling the overexpression of ERR $\alpha, V E G F-A$ expression in tumor was also stimulated in vivo in bone lesions induced by PC3-ERR $\alpha(E R R \alpha)(D)$ compared PC3-CT (CT) cells (C). (E) Decreased ERR $\alpha$ protein expression by transfection of three pooled siRNA sequences in parental PC3 cells shown by Western blot and $(\mathbf{F}-\mathbf{G})$ by real-time RT-PCR for $E R R \alpha$ and VEGF-A expression (Student's $t$-tests $P=0.0002$; $P=0.0027$ ). (H) Decreased $V E G F-A$ mRNA expression was also observed after XCT-790 treatment at $10^{-6} \mathrm{M}$ for $48 \mathrm{~h}$ in PC3-ERR $\alpha$ cells (Student's $t$-tests $P=0.006)$. (I- $-\mathbf{J})$ Real-time RT-PCR was performed on triplicate samples and normalized against the ribosomal protein gene $L 32$ to evaluate ERR $\alpha(P=0.0001)$ and VEGF-A $(P=0.0001)$ expression within subcutaneous (SC) tumors in vivo (pool of $n=3$ for each condition). (K-N) Similarly, to the PC3 model, IHC revealed that $E R R \alpha$ and $V E G F-A$ protein levels in tumors were increased in mixed lesions induced by PC3c-ERR $\alpha(\mathrm{ERR} \alpha)$ (L and N concomitantly) compared to PC3c-CT (CT) (K and M concomitantly) in vivo. Bar $=200 \mu \mathrm{m}$, T: Tumor; OB: osteoblasts; BM: Bone Matrix. 
and GSE74685) $(n=64, r=0.342, P=0.00572)$. Contrary to bone metastases specimens, a negative correlation with a weak Pearson $\mathrm{R}$ value was observed in primary CRPC tumor samples from combined microarray datasets GSE1034, GSE6919 and GSE2269 $(n=140, r=-0.178$, $P<0.0001$ ) (Table 1; Supplementary Table S1).

\section{Stimulation of stromal POSTN expression by tumor cells overexpressing ERR $\alpha$}

Given that WNT signaling is known to be recruited by the extracellular matrix protein PERIOSTINE (POSTN) in the stroma of at least certain tumor types and to participate in the steps required for cancer cell colonization and tumor progression [8], we next analyzed postn expression in our tumor models. By real time PCR, we found mouse postn expression up-regulated in PC3-ERR $\alpha$ versus PC3-CT SC tumors (Figure 7A). Immunostaining confirmed the stimulation of postn in peri-tumoral infiltrating cells in PC3-ERR $\alpha$ bone lesions (Figure 7B, a versus b), in PC3c-ERR $\alpha$ bone lesions (Figure 7C, a versus b) and in peri-tumoral cells in PC3-ERR $\alpha$ SC tumor versus PC3-CT SC tumors (Supplementary Figure $\mathrm{S} 1 \mathrm{~A}$ a versus $\mathrm{b}$ ). Vimentin expression was also addressed to show the stromal phenotype of the peri-tumoral cells expressing postn (Figure $7 \mathrm{Cc}$ ). Importantly, ERR $\alpha$ and posth expression levels were significantly positively correlated in bone metastases specimens $(n=44, r=0.528$, $P=0.00023$ ) (Table 1; Supplementary Table S1). A positive correlation was also found in adjacent normal tissue of primary CRPC tumors ( $n=184, r=0.401$, $P=<0.0001)$ confirming the stimulation of POSTN in peri-tumoral cells (Table1; Supplementary Table S1).

Postn has been shown to be stimulated in infiltrating stromal cells by factors secreted by breast cancer cells such as TGF $\beta[8,9]$. By real-time PCR, we found higher human TGFb1 expression in PC3-ERR $\alpha$ clones compared to PC3-CT (Figure 7D). Regulation of TGFb1 expression by ERR $\alpha$ in PCa cells was also confirmed by the lower levels of TGFb1 expression in ERR $\alpha$-SiRNA versus control sequences-transfected PC3 cells ( $\mathrm{Si}$ versus Sc, Figure 7E), in XCT-790 treated PC3-ERR $\alpha$ cells versus DMSO (Figure 7F) and by its stimulation in PC3-ERR $\alpha$ versus PC3-CT SC tumors in vivo (Figure 7G). Immunohistochemistry also confirmed higher $T G F b 1$ staining in tumor cells in PC3-ERR $\alpha$ (Figure $7 \mathrm{Hb}$ ) compared to PC3-CT-induced (Figure 7Ha) bone lesions in vivo and in PC3c-ERR $\alpha$ (Supplementary Figure $\mathrm{S} 1 \mathrm{Bb}$ ) compared to PC3c-CT-induced bone lesions in vivo (Supplementary Figure S1Ba). Finally, ERR $\alpha$ and TGFb1 expression levels were significantly positively correlated in primary CRPC tumor samples $(n=140, r=0.684$,
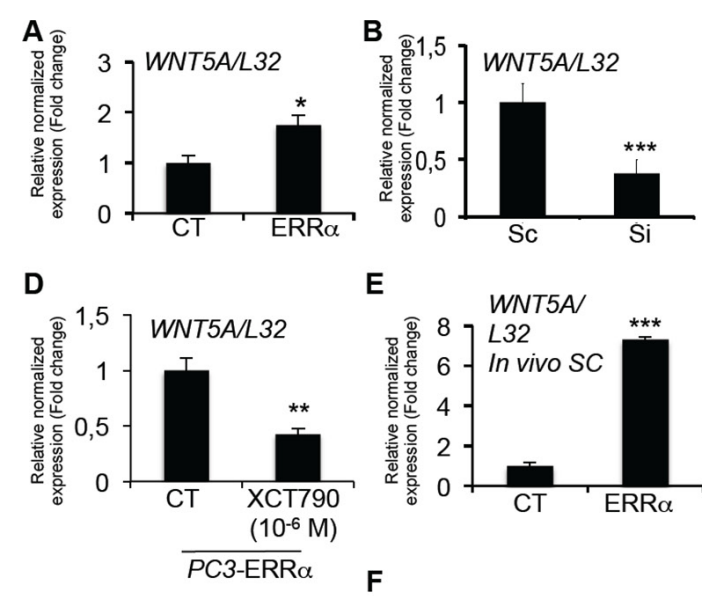

E
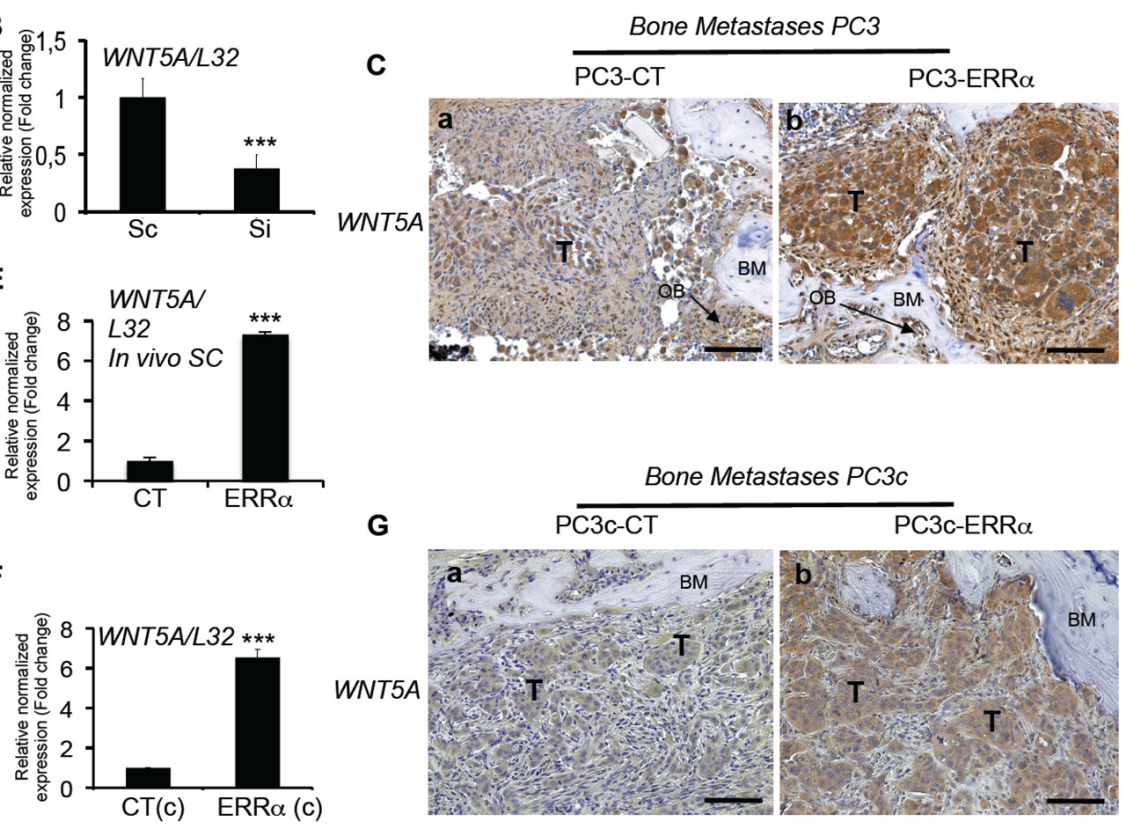

Figure 6: Stimulation of $\boldsymbol{W N T 5} \boldsymbol{A}$ expression in PCa cells by ERRa. (A) Assessment of $W N T 5 A$ expression by real-time RT-PCR on triplicate samples and normalized against the ribosomal protein gene L32. WNT5A (Student's $t$-tests $P=0.0305$ ) was higher in PC3ERR $\alpha$ versus PC3-CT (CT) cells in vitro. (B) WNT5A (Student's $t$-tests $P=0.0007$ ) mRNA expression was decreased in Si-ERR $\alpha$ (pooled of three SiRNA sequences) transfected cells compared to control-transfected (Sc) cells. (C) Paralleling the overexpression of ERR $\alpha$, WNT5A protein level expression was also stimulated in tumor in vivo in bone lesions induced by PC3-ERR $\alpha(E R R \alpha)(b)$ compared PC3CT (CT) cells (a). (D) Decreased WNT5A mRNA expression was also observed after XCT-790 treatment at $10^{-6} \mathrm{M}$ for $48 \mathrm{~h}$ in PC3-ERR $\alpha$ cells (Student's $t$-tests $P=0.0077$ ). (E) By real-time RT-PCR, we also found WNT5A mRNA expression (Student's $t$-tests $P=0.0001$ ) increased in PC3-ERR $\alpha$ SC tumors in vivo compared to PC3-CT SC tumors (F) WNT5A (Student's $t$-tests $P=0.0026)$ mRNA expression was also upregulated in the PC3c-ERR $\alpha((\operatorname{ERR} \alpha(\mathrm{c}))$ clone compared to the PC3c-CT $(\mathrm{CT}(\mathrm{c}))$ in vitro and $(\mathbf{G})$ in tumor in vivo in bone lesions induced by PC3c-ERR $\alpha(E R R \alpha)(b)$ compared PC3c-CT (CT) cells (a). Bar $=200 \mu \mathrm{m}$, T: Tumor; OB: osteoblasts; BM: Bone Matrix. 
Table 1: Meta-analysis using public datasets showing correlation between $E R R \alpha$ and $V E G F A$, WNT5A, POSTN and TGFb1 expression levels in bone metastases (GSE29650, GSE41619 and GSE74685) and/or in primary CRPC tumor (GSE1034, GSE6919 and GSE2269)

\begin{tabular}{|c|c|c|c|c|}
\hline & & & \multicolumn{2}{|c|}{ Number of samples $(\mathbf{N})$} \\
\hline Genes names & Database & Correlations & Primary tumour & Bone Metastases \\
\hline \multirow{2}{*}{ VEGFA/ERRA } & GSE21034/ GSE6919/ GSE32269 & $\begin{array}{l}\text { Pearson } \mathrm{R}=0.364 \\
P=0.00001\end{array}$ & $140 \mathrm{CRPC}$ & N/A \\
\hline & GSE29650/ GSE41619/GSE74685 & $\begin{array}{l}\text { Pearson } \mathrm{R}=0.646 \\
P=0.000001\end{array}$ & N/A & 64 \\
\hline \multirow{2}{*}{ WNT5A/ERRA } & GSE21034/ GSE6919/ GSE32269 & $\begin{array}{l}\text { Pearson } \mathrm{R}=-0.178 \\
P=0.035\end{array}$ & $140 \mathrm{CRPC}$ & N/A \\
\hline & GSE29650/ GSE41619/GSE74685 & $\begin{array}{l}\text { Pearson } \mathrm{R}=0.342 \\
P=0.00572\end{array}$ & N/A & 64 \\
\hline \multirow{2}{*}{ POSTN/ERRA } & GSE21034/ GSE6919/ GSE32269 & $\begin{array}{l}\text { Pearson } \mathrm{R}=0.401 \\
P=0.000001\end{array}$ & $\begin{array}{l}184 \text { in adjacent } \\
\text { normal tissue }\end{array}$ & N/A \\
\hline & GSE29650/ GSE41619 & $\begin{array}{l}\text { Pearson } \mathrm{R}=0.528 \\
P=0.00023\end{array}$ & N/A & 44 \\
\hline \multirow{2}{*}{ TGFb1/ERRA } & GSE21034/ GSE6919/ GSE32269 & $\begin{array}{l}\text { Pearson } \mathrm{R}=0.684 \\
P=0.000001\end{array}$ & $140 \mathrm{CRPC}$ & N/A \\
\hline & GSE29650/ GSE41619 & $\begin{array}{l}\text { Pearson } \mathrm{R}=-0.365 \\
\text { NS }\end{array}$ & N/A & 14 \\
\hline
\end{tabular}

To obtain z-scores, normalized data were $\log _{2}$ transformed and calculated by subtracting the population mean from individual expression values for each gene and then dividing the difference by the population standard deviation. Correlation scores were calculated using the Pearson correlation coefficient. $P$-values less than 0.05 were considered statistically significant.

$P=<0.0001$ ) (Table 1; Supplementary Table S1). On the contrary, no significant correlation was observed in bone metastases (Table 1; Supplementary Table S1). The data suggest that the upregulation of stromal cell POSTN may be the initial step through which ERR $\alpha$ induces rapid bone lesion progression.

\section{DISCUSSION}

Our findings indicate that $\mathrm{ERR} \alpha$ is a stimulator of prostate cancer cell progression in bone. In addition to confirming the regulation of the previously identified ERR $\alpha$-regulated gene, $V E G F-A$ [30] we identified $W N T 5 A$ and $T G F b 1$ as new ERR $\alpha$-regulated genes. Together with our observation that ERR $\alpha$ expression is higher in CRPC patients with bone metastases than without, and that ERR $\alpha$ in PCa alters molecular signaling in the stroma via the regulation of POSTN expression in infiltrating fibroblasts [10], our data provide new mechanistic insights into ERR $\alpha$-regulated pathways mediating PCa progression in bone.

ERR $\alpha$-positive prostate tumors have been associated with more invasive disease and a higher risk of recurrence [18]. For example, ERR $\alpha$ immunoreactivity score has been linked with Gleason scores [18]. ERR $\alpha$ was also recently associated with hypoxia adaptation in $\mathrm{PCa}$ cells (AR+ (LNCaP) and AR-(PC3) pre-clinical models), suggesting that $E R R \alpha$ might be involved in advanced progression of PCa [19]. Advanced PCa has a propensity of $90 \%$ to metastasize to bone, of $25 \%$ to metastasize to liver and to develop CRPC, all of which are associated with poor fiveyear survival rate [2].

Since we had shown that ERR $\alpha$ may be involved in bone metastases from breast cancer [22] that prompted us to determine if and how ERR $\alpha$ could contribute to malignant growth of PCa in bone. Interestingly, ERR $\alpha$ stimulation of PCa-induced bone lesion progression is different from what we observed in breast cancer [22]. ERR $\alpha$ plays a dual role in the progression of breast cancer -by promoting local tumor growth but by decreasing osteolytic lesions in bone, the latter due to the inhibition of osteoclast differentiation. The opposite activity of ERR $\alpha$ in PCa versus breast cancer on bone resorbing-cells may explain the differences in tumor progression in bone between breast and prostate cancers [22] and suggests distinct clinical management of prostate versus breast cancer patients with bone metastases.

ERR $\alpha$ expression levels in primary tumors and bone metastases associated with PCa patients correlated well with our results in three CRPC preclinical mouse models. At the cellular level, we found that ERR $\alpha$ directly stimulates both osteoclasts and osteoblasts, as well as factors in PCa cells thought to stimulate osteoclasts and osteoblasts, i.e., VEGF-A [33] [39]; WNT5A [37, 40, 41] and $T G F b 1[1,6,42]$ (Figure 8, pathways 1 and 2). Notably, all these factors were also found to correlate 
with $E R R \alpha$ expression in our meta-analysis studies of human PCa datasets.

Previously, WNT11 was shown to be regulated by $E R R \alpha$ in PCa cells and implicated in cancer cell invasion [43]. Our data on WNT5A and ERR expression in both in vivo and in vitro experiments and meta-analysis of human PCa datasets reinforces the link between $E R R \alpha$ activity and Wnt signaling. Interestingly, analysis of circulating tumor cells (CTC) from patients had indicate that $W N T 5 A$ is activated, in keeping with a role for $W N T 5 A$ in cell polarization and cancer cell invasion [44, 45, 46]. Indeed, analysis of CTCs from patients progressing on AR inhibitor compared with untreated case indicates activation of WNT5A [46]. Moreover, Miyamoto $\mathrm{D}$ et al. show that ectopic expression of $W N T 5 A$ inhibits the anti-proliferative effect of AR inhibition suggesting that it may participate in the acquisition of resistance to androgen deprivation and to treatment failure [46].
However, WNT5A has variously been described as a pro or an inhibitor of tumor growth in bone [47, 48]. Our results suggest that ERR $\alpha$-mediated $W N T 5 A$ is associated with advanced PCa metastatic disease in bone, but to fully understand the molecular mechanisms and determine direct versus indirect regulation by $E R R \alpha$ in tumor cells, additional studies are required. Nevertheless, the identification of $W N T 5 A$ as an ERR $\alpha$-regulated gene may represent implications for its potential use as a prognostic marker in prostate cancer.

With respect to $\mathrm{PCa}$-induced osteolysis, we found that rankl expression was stimulated in MC3T3-E1 cells co-cultured with PC3-ERR $\alpha$ but not with the ACE-1 cell model, which is a mixed lesion model, whether or not ERR $\alpha$ levels were modified in the latter. These data suggest indirect regulatory effects on osteoclasts that participate in the resorption observed in bone lesions in animals bearing ERR $\alpha$ osteolytic tumors but not mixed

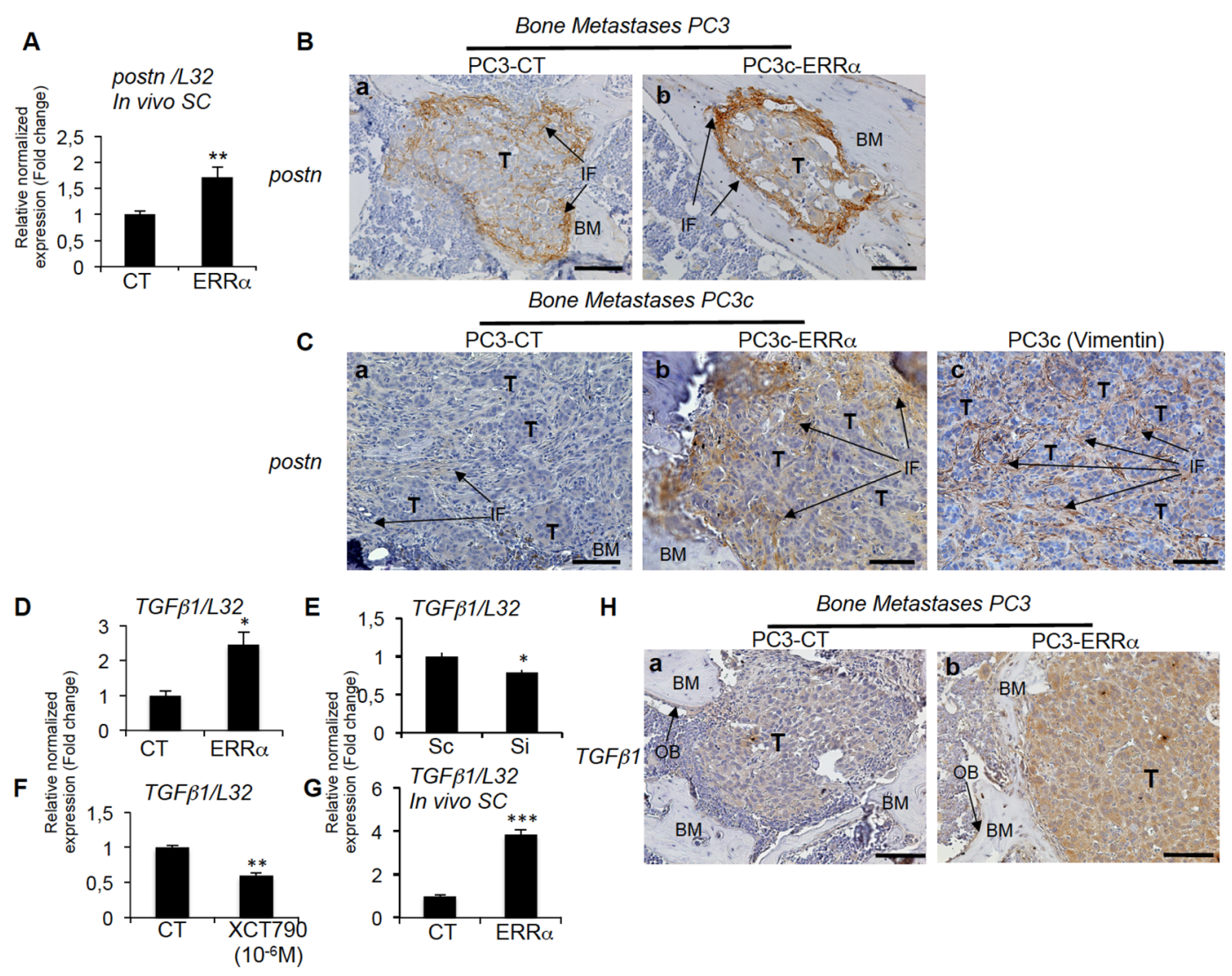

Figure 7: Regulation of stromal postn by ERRa. (A) Assessment of the mouse postn expression by real-time RT-PCR on triplicate samples and normalized against the mouse ribosomal protein gene L32. Real-time RT-PCR showed increased postn mRNA expression (Student's $t$-tests $P=0.0026$ ) in PC3-ERR $\alpha$-induced SC tumors in vivo. (B) Increased expression of postn in peri-tumoral and infiltrating fibroblasts was visualized by IHC on PC3-ERR $\alpha$-induced bone lesions (b) compared to PC3-CT (a). (C) Similarly, postn protein was upregulated in the infiltrating fibroblasts in vivo in bone lesions induced by PC3c-ERR $\alpha(\mathrm{ERR} \alpha)(\mathrm{b})$ compared PC3c-CT (CT) cells (a). Vimentin antibody was used to show the fibroblastic type of the postn expressing cells (c) (D) Real-time RT-PCR showed that $T G F b 1 \mathrm{mRNA}$ expression (Student's $t$-tests $P=0.0246$ ) was higher in PC3-ERR $\alpha$ versus PC3-CT (CT) cells in vitro while (E) TGFb1 (Student's $t$-tests $P=0.022)$ mRNA expression was decreased in Si-ERR $\alpha$ (pooled of three sequences) transfected cells compared to control-transfected (Sc) cells. (F) Real-time RT-PCR also showed decreased TGFb1 mRNA expression (Student's $t$-tests $P=0.0033$ ) in XCT790 treated PC3-ERR $\alpha$ cells and $(\mathbf{G})$ increased TGFb1 mRNA expression (Student's $t$-tests $P=0.0002$ ) in PC3-ERR $\alpha$-induced SC tumors $i n$ vivo. (H) TGFb1 staining was higher in PC3-ERR $\alpha$ (b) compared to PC3-CT (a) in tumor-induced bone lesions in vivo. Bar $=200 \mu \mathrm{m}$. T: Tumor; OB: osteoblasts; BM: Bone Matrix; IF: infiltrating fibroblasts. 
lesions (Figure 8, pathway 3).

Our data suggest that ERR $\alpha$ may also have an impact on the stromal microenvironment. The reciprocal interaction between cancer cells and tissue-specific stroma is known to be critical for primary and metastatic tumor growth progression and POSTN is one of the extracellular matrix molecules known to participate in tumor proliferation and invasion when secreted from stromal cells infiltrating tumors $[8,10,11]$. Here, we confirm that postn is not only expressed in the stromal cells infiltrating tumors of bone xenografts but also in orthotopic PCa xenografts [10]. However, we also show for the first time that mouse postn expression can be stimulated by $\mathrm{PCa}$ cells overexpressing ERR $\alpha$ in bone and in SC tumors in vivo. Our data also suggest that ERR $\alpha$ may participate in the initial expansion of cancer cells by regulating the extracellular matrix component postn in stromal cells infiltrating tumors at least in part through the regulation of $T G F b 1$ in prostate cancer cells (Figure 8, pathway 4) [8]. The link between ERR $\alpha / P O S T N$ in the clinical models was confirmed by our meta-analyses of bone metastases and in tumor adjacent tissues in primary tumors, which suggests that POSTN may constitute a new prognostic marker in association with ERR $\alpha$. The data also suggest that this is may be the initial step by which ERR $\alpha$ induces rapid bone lesion progression. Consequently, targeting the tumor microenvironment may also constitute a new therapeutic approach for prostate cancer patients with high levels of $\mathrm{ERR} \alpha$ [49]

Very recently, the ERR $\alpha$ coactivator PGC1 $\alpha$ has been described as a suppressor of PCa metastasis [50]. PGC1 $\alpha$ is expressed at very low levels (i.e., CT: 33 ) in our PC3, PC $3 \mathrm{c}$ models, suggesting that the ERR $\alpha-\mathrm{PGC} 1 \alpha$ mechanisms described by Torrano et al. are unlikely to occur in these models. Taken together, these data suggest that ERR $\alpha$ is a suppressor when PGC1 $\alpha$ is highly expressed and as an activator when PGC1 $\alpha$ expression is low, in turn strongly suggesting that, depending on the expression of ERR $\alpha$ cofactors in PCa cells, ERR $\alpha$ can have opposite activities. Thus, it will be important to take into account not only the expression of ERR $\alpha$ but also its cofactors in tumors specimens.

In conclusion, we report for the first time on the involvement of ERR $\alpha$ in the steps of $\mathrm{PCa}$ initiation and tumor progression in bone, which results from ERR $\alpha$ modifications of signaling molecules and the microenvironment. Our findings contribute to a new understanding of mechanisms underlying the overall negative clinical outcome associated with ERR $\alpha$ in prostate cancer and provide a rationale for the investigation of ERR $\alpha$ as a therapeutic target to treat primary prostate cancers and their associated bone metastases.

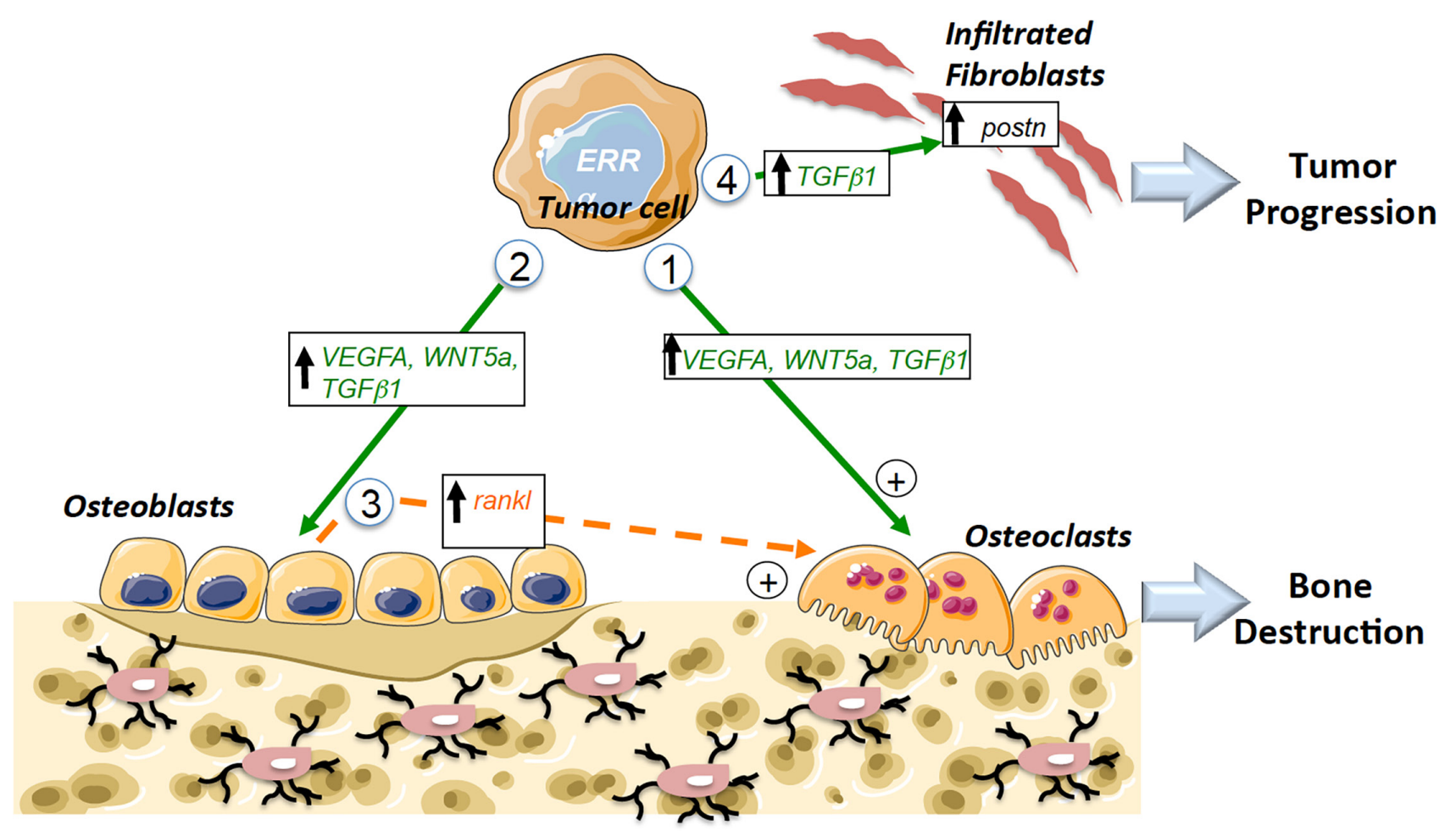

Figure 8: Schematic diagram showing ERR $\alpha$ pathways that can mediate tumor progression in bone. Pathway 1: Increased expression of pro-resorption factors (VEGF-A, WNT5A, TGF 1 ) in PCa tumors overexpressing ERR $\alpha$ leads to direct stimulation of Oc formation. Pathway 2: Increased expression of pro-osteoblastic factors (VEGF-A, WNT5A, TGF $\beta 1)$ in PCa tumors overexpressing ERR $\alpha$ that leads to direct stimulation of $\mathrm{Ob}$ formation. Pathway 3: Indirect stimulation of osteoclasts through osteoblasts (via the regulation of $\mathrm{rankl}$ in $\mathrm{Ob}$ for the osteolytic model). Pathway 4: Stimulation of the metastatic niche through the stimulation of postn in fibroblasts infiltrating tumors by TGFB1 secreted by tumor cells. Ob: osteoblast; Oc: osteoclast; direct signaling (in green), indirect signaling (in orange). 


\section{MATERIALS AND METHODS}

\section{Ethics approval}

SCID male mice were purchased from Charles River and handled according to the French Ministerial Decree No.87-848 of 19 October 1987. Experimental protocols were approved by the Institutional Animal Care and Use Committee at the Université Lyon-1 (France) (CEEA-55 Comité d'Ethique en Expérimentation Animale DR201432). Studies involving human primary prostate tumors were carried out according to the principles embodied in the Declaration of Helsinki.

\section{PCa patient primary and bone metastases specimens for IHC}

Autopsy files (dating from 1991 to 1998) from the Department of Pathology (Tumor Tissue Bank, Centre Hospitalier Universitaire de Liège, Belgium) were screened for diagnosis of disseminated prostate cancer with histologically proven bone metastases [51]. For immunohistochemistry (IHC) analysis, we selected a prostate cancer patient who died with disseminated disease, including bone metastases. We retrieved patient slides and their clinical history. Tumors were fixed and paraffin-embedded.

\section{Meta-analysis}

For correlation analysis in clinical samples, gene expression data and corresponding clinical annotations for previously published datasets on normal prostate tissue, adjacent prostate tissue, primary and bone metastases were downloaded from the Gene-Expression-Omnibus (GSE6919-GSE29650-GSE32269-GSE41619-GSE21034GSE74685) (Supplementary Table S1). To obtain z-scores, normalized data were $\log _{2}$ transformed and calculated by subtracting the population mean from individual expression values for each gene and then dividing the difference by the population standard deviation. Correlation scores were calculated using the Pearson correlation coefficient. $P$-values less than 0.05 were considered statistically significant. Statistical significance was determined by GraphPad Prism v 5.02 using the twosided student $t$-test.

\section{Animal studies}

SCID male mice, 6 weeks of age, were housed in barrier conditions under isolated laminar flow hoods. Mice bearing tumor xenografts were closely monitored for established signs of distress and discomfort and were humanely euthanized.

PC3 cells induce osteolytic lesions, PC3c cells induce mixed lesions with lytic and osteoblastic regions in the bone marrow cavity [28] while ACE-1 mainly induce lytic lesions in the bone marrow cavity and osteoblastic region outside the bone (spicules) [29].

Intra-osseous tumor xenograft experiments were performed as previously described [28] as for technical reason, we could not obtain bone lesions after intraarterial and intra-cardiac injections. PC3, PC3c and ACE1 cells $\left(6 \times 10^{5}\right.$ in $15 \mu \mathrm{L}$ PBS $)$ were injected in the bone marrow cavity [28]. Mice were sacrificed after 3 weeks (PC3 and ACE-1) and 6 weeks (PC3c). Radiographs (LifeRay HM Plus, Ferrania) of animals were taken at that time after inoculation using X-ray (MX-20; Faxitron $\mathrm{X}$-ray Corporation). Animals were sacrificed, hind limbs were collected for histology and histomorphometrics analyses. The bone lesion surface, that includes lytic and osteoblastic regions, was measured using the computerized image analysis system MorphoExpert (Exploranova). The extent of bone lesions for each animal was expressed in $\mathrm{mm}^{2}$. Tibiae were scanned using microcomputed tomography (Skyscan1174, Skyscan) with an $8.1 \mu \mathrm{M}$ voxel size and an X-ray tube $(50 \mathrm{kV} ; 80 \mu \mathrm{A})$ with $0.5 \mu \mathrm{m}$ aluminum filter. Three-dimensional reconstructions and rendering were performed using the manufacturer's suite (Respectively, NRecon\&CTVox, and Skyscan). Bone Volume/Tissue Volume: (\%BV/TV) includes residual trabecular and remaining cortical bone for PC3 and ACE1 models, plus new bone formation into the bone marrow cavity for PC3c model. For the ACE-1 model, since the osteoblastic lesions is outside the cortical bone, the percent (\%) of extra-new bone spicules formation (only spicules surface) with respect to total volume (trabecular, cortical and spicule) (for the ACE model) were quantified. \%BV/ $\mathrm{TV}$ and $\%$ of extra-new bone spicules formation were carried out with CTAn (version 1.9, Skyscan) and CTVol (version 2.0, Skyscan) software. Dissected bones were then processed for histological and histomorphometric analysis (tumor burden-to-soft tissue volume (\%TB/STV)) and TRAP-positive trabecular bone surface (Oc.S) to the total bone surface (BS) as described previously for the PC3 model [22]. Results were plotted as the mean \pm SD.

Subcutaneous injections of PC 3 cells $\left(10^{6}\right.$ in $100 \mu \mathrm{l}$ PBS) were also performed in 6- to 8-week-old SCID mice. Mice were sacrificed after 6 weeks and tumors were fixed and embedded in paraffin.

\section{Cell lines and transfection}

The PC3 cell line was obtained from the American Type Culture Collection (ATCC) (cell line authentication was performed). The PC3c cells, a subculture cell line of PC3 was isolated in our laboratory in vitro after single cell population culture. Consequently to spontaneous derivation of the cells, we finally obtained a subculture cell line named PC 3c which was chosen based on its epithelial phenotype [28]. Osteoprotegerin (OPG) and endothelin-1 (ET1) are highly expressed by $\mathrm{PC} 3 \mathrm{c}$ while 
dikkopf-1 (DKK1) expression is decreased. Finally, PC3c highly expressed bone associated markers osteopontin, Runx2, alkalin phosphatase, bone sialoprotein and produced mineralized matrix in vitro in osteogenic conditions showing a strong osteomimetism phenotype of PC3c cells compared to PC3 [28]. ACE-1 were obtained from Dr T Rosol [29]. PC3 and ACE-1 stably transfected clones were routinely cultured in F12K (Gibco/Life Technologies) and PC3c clones were cultured in DMEM. All cultures were supplemented with $10 \%(\mathrm{v} / \mathrm{v})$ fetal bovine serum (Perbio/Thermo Scientific) and 1\% (v/v) penicillin/streptomycin (Life technologies) at $37^{\circ} \mathrm{C}$ in a $5 \% \mathrm{CO}_{2}$ incubator.

Human $E R R \alpha \operatorname{cDNA}(E R R \alpha)$ and the dominant negative form mutated into the co-activator domain AF2 (AF2) was obtained previously [22]. Cells were cultured under clonal selection for 4 weeks in the presence of puromycin $(1 \mu \mathrm{g} / \mathrm{mL})$ (Life Technologies). PC3 cells were also transfected $(100$ pmol $)$ with ERR $\alpha$-siRNA sequences specific to human (ONTARGET plus Human ESRRA SMART pool of three sequences: GGCCUUCGCUGAGGACUUA / GCGAGAGGAGUAUGUUCUA/GGGUGGGCAUGC UCAAGGA) and control sequences (ON-TARGET plus Human Non-targeting pool of three sequences: UGGUUUACAUGUCGACUAA/UGGUUUACAUGUU GUGUGA/UGGUUUACAUGUUUUCCUA) (Dharmacon) and mRNA were extracted at $72 \mathrm{~h}$ after transfection. Conditioned medium from $\mathrm{PC} 3$ and $\mathrm{PC} 3 \mathrm{c}$ clones (used on primary calvaria cells culture) and PC3 parental cells treated with the XCT-790 at $10^{-6} \mathrm{M}$ (Sigma) was obtained after 48 hours in $\alpha$-MEM supplemented with $0.5 \%$ of serum, then filter sterilized and proteins quantified to use equal concentration of proteins for each conditions $(25 \mu \mathrm{g})$. Dimethyl sulfoxide (DMSO) was used as control (CT). PC3-ERR $\alpha$ cells (pool of three clones) were treated with the inverse agonist XCT-790 at $10^{-6} \mathrm{M}$ (Sigma) for $48 \mathrm{~h}$. DMSO was used as control (CT).

\section{Osteoclastogenesis assay}

Bone marrow cells from 6-week-old OF1 male mice were cultured for 7 days as previously described [22]. Pools of PC3-CT/PC3-ERR $\alpha$ clones or PC3c-CT/PC3c$\mathrm{ERR} \alpha$ or ACE-1-CT/ ERR $\alpha / \mathrm{AF} 2$ were plated $\left(10^{4}\right.$ cells $)$ on day 1 on bone marrow cells culture in presence of rankl and $m$-csf. Mature osteoclasts were stained for TRAP activity (Sigma-Aldrich). Multinucleated TRAP-positive cells containing three or more nuclei were counted as osteoclasts. Results were plotted as the mean $\pm \mathrm{SD}$ of three wells for each condition and were representative of two independent experiments.

\section{Osteoblastogenesis assay}

Cells were enzymatically isolated from the calvaria as described previously [31]. Mouse calvaria cells were continuously exposed (21 days) to conditioned medium isolated from cultures of PC3 pooled clones or PC3c clones. Wells were stained with von Kossa stain for ALP and bone nodules were counted on a grid [31]. Results were plotted as the mean number of nodules \pm SD of three wells and were representative of two independent experiments. The murine osteoblastic MC3T3-E1 cell line was cultured for 2 weeks with pooled PC3-CT versus PC3-ERR $\alpha$ clones or ACE-1-CT/ERR $\alpha / A F 2$ that were plated $\left(10^{4}\right.$ cells $)$ on day 1 for 2 weeks. mRNA were then extracted and osteoblastic markers expression addressed by real-time PCR.

\section{Immunohistochemistry}

Tibia bearing metastases were fixed and embedded in paraffin. IHC analysis was performed by incubating sections overnight with rabbit monoclonal against human and mouse anti-VEGF-A (1/50) (Abcam), rabbit polyclonal antibodies against human and mouse WNT5a $(1 / 70)($ Abcam), goat anti-mouse postn (1/200)(R\&D), mouse monoclonal anti- human/mouse TGFbl (1/40) (R\&D), rabbit polyclonal anti-mouse vimentin(1/50) (Biovision) and mouse monoclonal anti-human/mouse $E R R \alpha$ antibody (1/50)(Santa Cruz) [22]. Sections were then incubated with HRP-conjugated anti-mouse (Dako), anti-rabbit (Dako) or the anti-goat (Jackson) antibodies for 1hour and stained using 3,3'-diaminobenzidine (Dako). Counterstaining was performed using Mayer's hematoxylin (Merck).

\section{Immunoblotting}

Protein extraction and immunoblotting were performed as described previously [22]. As the mouse monoclonal anti-human/mouse ERR $\alpha$ antibody (Santa Cruz) did not work in Western-blots, we used a rabbit monoclonal antibody against $E R R \alpha$ (Epitomics) (1:400) [22] and a rabbit polyclonal antibody against GAPDH (Abcam) $(1: 10,000)$ (Amersham) as a protein loading control.

\section{Real time RT-PCR}

Total RNA was extracted with Trizol reagent (Life Technologies) and $2 \mu \mathrm{g}$ was reverse-transcribed using Superscript ${ }^{\mathrm{TM}}$ II (Life Technologies) [22]. Realtime PCR was performed on a Mastercycler-ep-Realplex (Eppendorf) with primers specific to human and mouse genes (Supplementary Table S2) using Quantifast SYBR Green (Life Technologies). PCR was carried out according to the manufacturer's instructions. Melting curve analysis was used to verify that a single peak was obtained for each product with a 95-100\% PCR efficiency (Roche software). Relative gene expression levels were normalized according to the $\mathrm{Ct}$ value of the housekeeping gene encoding the ribosomal protein L32 and results were expressed as fold differences equal to $2^{-\Delta \Delta \mathrm{Ct}}$. 


\section{Statistical analysis}

Statistical analysis was performed using GraphPad Prism software (San Diego,USA). Pairwise comparisons were tested using a non-parametric Mann-Whitney $U$ test for bone metastases. In vitro data were analyzed using ANOVA and Student's $t$-tests to assess the differences between groups. Results of $P<0.05$ were considered significant.

\section{ACKNOWLEDGMENTS}

We are grateful to the Animalerie Lyon Est Conventionnelle (ALECS) and to D. Sahay for discussion.

\section{CONFLICTS OF INTEREST}

No potential conflicts of interest were disclosed.

\section{GRANT SUPPORT}

This work was supported by the Association pour la recherche sur les tumeurs de la prostate (ARTP), the National Center for Scientific Research (CNRS) to EB and by the National Institute of Health and Medical Research (INSERM) and the University of Lyon1. AF was supported by the Ligue nationale contre le cancer and the Fondation pour la recherche médicale (FRM), MB, MG by the French National Cancer Institute (INCa), CD by the Institut Pasteur/Région Nord-Pas-de-Calais, GV by the Labex DEVweCAN and AB from the Belgian National Fund for Scientific Research. CK is a recipient of the H2020 Marie Sklodowska-Curie Individual Fellowship under agreement number (655777-miROMeS).

\section{REFERENCES}

1. Weilbaecher KN, Guise TA, McCauley LK. Cancer to bone: a fatal attraction. Nat Rev Cancer. 2011; 11:411-25.

2. Park JC, Eisenberger MA. Advances in the Treatment of Metastatic Prostate Cancer. Mayo Clin Proc. 2015; 90:1719-33.

3. Coleman R GM, Morgan G, Clezardin P. Effects of bonetargeted agents on cancer progression and mortality. J Natl Cancer Inst. 2012; 104:1059-67.

4. Logothetis $\mathrm{CJ}$, Lin SH. Osteoblasts in prostate cancer metastasis to bone. Nat Rev Cancer. 2005; 5:21-8.

5. Boyle WJ, Simonet WS, Lacey DL. Osteoclast differentiation and activation. Nature. 2003; 423:337-42.

6. Tang YS and Allistona, T. Regulation of postnatal bone homeostasis by TGF $\beta$. Bonekey Rep. 2013; 2(255).

7. Hall CL, Bafico A, Dai J, Aaronson SA, Keller ET. Prostate cancer cells promote osteoblastic bone metastases through Wnts. Cancer Res. 2005; 65:7554-60.
8. Malanchi I, Santamaria-Martínez A, Susanto E, Peng H, Lehr H, Delaloye J, Huelsken J. Interactions between cancer stem cells and their niche govern metastatic colonization. Nature. 2011; 481:85-9.

9. Liu AY, Zheng H, Ouyang G. Periostin, a multifunctional matricellular protein in inflammatory and tumor microenvironments. Matrix Biol. 2014; 37:150-6.

10. Özdemir B, Hensel J, Secondini C, Wetterwald A, Schwaninger R, Fleischmann A, Raffelsberger W, Poch O, Delorenzi M, Temanni R, Mills IG, van der Pluijm G, Thalmann GN, et al. The molecular signature of the stroma response in prostate cancer-induced osteoblastic bone metastasis highlights expansion of hematopoietic and prostate epithelial stem cell niches. PLoS One. 2014; 9.

11. Ghajar CM PH, Mori H, Matei IR, Evason KJ, Brazier H, Almeida D, Koller A HK, Stainier DY, Chen EI, Lyden D, Bissell MJ. The perivascular niche regulates breast tumour dormancy. Nat Cell Biol. 2013; 15:807-17.

12. Benoit G, Cooney A, Giguere V, Ingraham H, Lazar M, Muscat G, Perlmann T, Renaud TJ, Schwabe J, Sladek F, Tsai MJ, Laudet V. International Union of Pharmacology. LXVI. Orphan nuclear receptors. Pharmacol Rev. 2006; 58:798-836.

13. Giguere V, Yang N, Segui P, Evans RM. Identification of a new class of steroid hormone receptors. Nature. 1988; 331:91-4.

14. Kallen J, Schlaeppi JM, Bitsch F, Filipuzzi I, Schilb A, Riou V, Graham A, Strauss A, Geiser M, Fournier B. Evidence for ligand-independent transcriptional activation of the human estrogen-related receptor alpha (ERRalpha): crystal structure of ERRalpha ligand binding domain in complex with peroxisome proliferator-activated receptor coactivator-1alpha. J Biol Chem. 2004; 279:49330-7.

15. Wei W, Schwaid A, Wang X, Wang X, Chen S, Chu Q, Saghatelian A, Wan Y. Ligand Activation of ERR $\alpha$ by Cholesterol Mediates Statin and Bisphosphonate Effects. Cell Metab. 2016; 23:479-91.

16. Busch BB, Stevens WC Jr, Martin R, Ordentlich P, Zhou S, Sapp DW, Horlick RA, Mohan R. Identification of a selective inverse agonist for the orphan nuclear receptor estrogenrelated receptor alpha. J Med Chem. 2004; 47:5593-6.

17. Ariazi EA, Clark GM, Mertz JE. Estrogen-related receptor alpha and estrogen-related receptor gamma associate with unfavorable and favorable biomarkers, respectively, in human breast cancer. Cancer Res. 2002; 62:6510-8.

18. Fujimura T, Takahashi S, Urano T, Kumagai J, Ogushi T, Horie-Inoue K, Ouchi Y, Kitamura T, Muramatsu M, Inoue $\mathrm{S}$. Increased expression of estrogen-related receptor alpha (ERRalpha) is a negative prognostic predictor in human prostate cancer. Int J Cancer. 2007; 120:2325-30.

19. Zou C, Yu S, Xu Z, Wu D, Ng C, Yao X, Yew DT, Vanacker JM, Chan FL. ERR $\alpha$ augments HIF-1 signalling by directly interacting with HIF-1 $\alpha$ in normoxic and hypoxic prostate cancer cells. J Pathol. 2014; 233:61-73. 
20. Teyssier C, Bianco S, Lanvin O, Vanacker JM. The orphan receptor ERRalpha interferes with steroid signaling. Nucleic Acids Res. 2008; 36:5350-61.

21. Bonnelye E, Aubin JE. An energetic orphan in an endocrine tissue: a revised perspective of the function of estrogen receptor-related receptor alpha in bone and cartilage. J Bone Min Res. 2013; 28:225-33.

22. Fradet A, Sorel H, Bouazza L, Goehrig D, Depalle B, Bellahcene A, Castronovo V, Follet H, Descotes F, Aubin JE, Clezardin P, Bonnelye E. Dual function of ERRalpha in breast cancer and bone metastasis formation: implication of VEGF and osteoprotegerin. Cancer Res. $2011 ; 71: 5728-38$

23. Robinson D, Van Allen EM, Wu YM, Schultz N, Lonigro RJ, Mosquera JM, Montgomery B, Taplin ME, Pritchard CC, Attard G, Beltran H, Abida W, Bradley RK, et al. Integrative clinical genomics of advanced prostate cancer. Cell. 2015; 161:1215-28.

24. Taylor BS, Schultz N, Hieronymus H, Gopalan A, Xiao Y, Carver BS, Arora VK, Kaushik P, Cerami E, Reva B. Integrative genomic profiling of human prostate cancer. Cancer Cell. 2010; 18:11-22.

25. Chandran U, Ma C, Dhir R, Bisceglia M, Lyons-Weiler M, Liang W, Michalopoulos G, Becich M, Monzon FA. Gene expression profiles of prostate cancer reveal involvement of multiple molecular pathways in the metastatic process. BMC Cancer. 2007; 12:64.

26. Cai C, Wang H, He HH, Chen S, He L, Ma F, Mucci L, Wang Q, Fiore C, Sowalsky AG, Loda M, Liu XS, Brown $\mathrm{M}$, et al. ERG induces androgen receptor-mediated regulation of SOX9 in prostate cancer. J Clin Invest. 2013; 123:1109-23.

27. Akech J, Wixted JJ, Bedard K, van der Deen M, Hussain S, Guise TA,van Wijnen AJ, Stein JL, Languino LR, Altieri DC, Pratap J, Keller E, Stein GS, et al. Runx2 association with progression of prostate cancer in patients: mechanisms mediating bone osteolysis and osteoblastic metastatic lesions. Oncogene. 2010; 29:811-21.

28. Fradet A SH, Depalle B, Serre CM, Farlay D, Turtoi A, Bellahcene A, Follet HCV, Clézardin P, Bonnelye E. A new murine model of osteoblastic/osteolytic lesions from human androgen-resistant prostate cancer. PLoS One. 2013; 8:e75092.

29. LeRoy BE, Thudi NK, Nadella MV, Toribio RE, TannehillGregg SH, van Bokhoven A, Davis D, Corn S, Rosol TJ. New bone formation and osteolysis by a metastatic, highly invasive canine prostate carcinoma xenograft. Prostate. 2006; 66:1213-22.

30. Stein RA, Gaillard S, McDonnell DP. Estrogen-related receptor alpha induces the expression of vascular endothelial growth factor in breast cancer cells. J Steroid Biochem Mol Biol. 2009; 114:106-12.

31. Bonnelye E, Merdad L, Kung V, Aubin JE. The orphan nuclear estrogen receptor-related receptor alpha (ERRalpha) is expressed throughout osteoblast differentiation and regulates bone formation in vitro. J Cell Biol. 2001; 153:971-84.

32. Zelzer E OB. Multiple roles of vascular endothelial growth factor (VEGF) in skeletal development, growth, and repair. Curr Top Dev Biol. 2005; 169-87.

33. $\mathrm{Hu} \mathrm{K}$, Olsen BR. Osteoblast-derived VEGF regulates osteoblast differentiation and bone formation during bone repair. J Clin Invest. 2016; 126:509-26.

34. Larson S, Zhang X, Dumpit R, Coleman I, Lakely B, Roudier M, Higano CS, True LD, Lange PH, Montgomery B, Corey E, Nelson PS, Vessella RL, et al. Characterization of osteoblastic and osteolytic proteins in prostate cancer bone metastases. Prostate. 2013; 73: 932-40.

35. Haider M, Zhang X, Coleman I, Ericson N, True LD, Lam HM, Brown LG, Ketchanji M, Nghiem B, Lakely B, Coleman R, Montgomery B, Lange PH1, et al. Epithelial mesenchymal-like transition occurs in a subset of cells in castration resistant prostate cancer bone metastases. Clin Exp Metastasis. 2016; 33:239-48.

36. Hornberg E, Ylitalo EB, Crnalic S, Antti H, Stattin P, Widmark A, Bergh A, Wikstrom P. Expression of androgen receptor splice variants in prostate cancer bone metastases is associated with castration-resistance and short survival. PLoS One. 2011; 6:e19059.

37. Maeda K, Kobayashi Y, Udagawa N, Uehara S, Ishihara A, Mizoguchi T, Kikuchi Y, Takada I, Kato S, Kani S. Wnt5aRor2 signaling between osteoblast-lineage cells and osteoclast precursors enhances osteoclastogenesis. Nat Med. 2012; 18:405-12.

38. Auld KL, Berasi SP, Liu Y, Cain M, Zhang Y, Huard C, Fukayama S, Zhang J, Choe S, Zhong W, Bhat B.M, Bhat RA, Brown EL, et al. Estrogen-related receptor alpha regulates osteoblast differentiation via $\mathrm{Wnt} /$ beta-catenin signaling. J Mol Endocrinol. 2012; 48:177-91.

39. Kusumbe AP, Ramasamy SK, Adams RH. Coupling of angiogenesis and osteogenesis by a specific vessel subtype in bone. Nature. 2014; 507:323-8.

40. Bellon M, Ko N, Lee M, Yao Y, Waldmann T, Trepel J, Nicot C. Adult T-cell leukemia cells overexpress Wnt5a and promote osteoclast differentiation. Blood. 2013; 121:5045-54.

41. Kobayashi Y, Uehara S, Udagawa N, Takahashi N. Regulation of bone metabolism by Wnt signals. J Biochem. 2016; 159:387-92.

42. Fournier PGJ, Juárez P, Jiang G, Clines GA, Niewolna M, Kim HS, Walton HW, Peng XH, Liu Y, Mohammad KS, Wells CD, Chirgwin JM, Guise TA. The TGF- $\beta$ Signaling Regulator PMEPA1 Suppresses Prostate Cancer Metastases to Bone. Cancer Cell. 2015; 27:809-21.

43. Dwyer MA, Joseph JD, Wade HE, Eaton ML, Kunder RS, Kazmin D, Chang CY, McDonnel DP. WNT11 expression is induced by estrogen-related receptor alpha and beta- 
catenin and acts in an autocrine manner to increase cancer cell migration. Cancer Res. 2010; 70:9298-308.

44. Kikuchi A, Yamamoto H, Sato A, Matsumoto S. Wnt5a: its signalling, functions and implication in diseases. 2012; Acta Physiol(204):1.

45. Weeraratna A, Jiang Y, Hostetter G, Rosenblatt K, Duray P, Bittner M, Trent JM. Wnt5a signaling directly affects cell motility and invasion of metastatic melanoma. Cancer Cell. 2002; 1:279-88.

46. Miyamoto D, Zheng Y, Wittner BS, Lee RJ, Zhu H, Broderick KT, Desai R, Fox DB, Brannigan BW, Trautwein J, Arora KS, Desai N, Dahl DM, et al. RNASeq of single prostate CTCs implicates noncanonical Wnt signaling in antiandrogen resistance. 2015; 349:1351-6.

47. Lee G, Kang DI, Ha YS, Jung YS, Chung J, Min K, Kim TH, Moon KH, Chung JM, Lee DH, Kim WJ, Kim IY. Prostate cancer bone metastases acquire resistance to androgen deprivation via WNT5A-mediated BMP-6 induction. Br J Cancer. 2014 18; 110:1634-44.
48. Thiele S, Göbel A, Rachner TD, Fuessel S, Froehner M, Muders MH, Baretton GB, Bernhardt R, Jakob F, Glüer CC, Bornhäuser M, Rauner M, Hofbauer LC. WNT5A has antiprostate cancer effects in vitro and reduces tumor growth in the skeleton in vivo. J Bone Min Res. 2015; 30:471-80.

49. Nuzzo PV, Buzzatti G, Ricci F, Rubagotti A, Argellati F, Zinoli L, Boccardo F. Periostin: a novel prognostic and therapeutic target for genitourinary cancer? Clin Genitourin Cancer. 2014; 12:301-11.

50. Torrano V, Valcarcel-Jimenez L, Cortazar AR, Liu X, Urosevic J, Castillo-Martin M, Fernández-Ruiz S, Morciano G, Caro-Maldonado t A, Pandya P, LA, Guiu M, Zúñiga-García P, et al. The metabolic co-regulator PGC1 $\alpha$ suppresses prostate cancer metastasis. Nat Cell Biol. 2016; 18:645-56.

51. Waltregny D BA, de Leval X, Florkin B, Weidle U, Castronovo V. Increased expression of bone sialoprotein in bone metastases compared with visceral metastases in human breast and prostate cancers. J Bone Min Res. 2000; $15: 834-43$. 